\title{
PLANO DE AMOSTRAGEM SEQÜENCIAL PARA O MONITORAMENTO DE PERCEVEJOS, LEPTOGLOSSUS STIGMA (HEMIPTERA: COREIDAE) NA CULTURA DA GOIABA
}

\author{
Alfredo LUIZ VENZEL DE OLIVEIRA \\ Bacharel em Estatística
}

Orientadora: Prof ${ }^{a}$ Dr ${ }^{a}$ SÔNIA MARIA DE STEFANO PIEDADE

\begin{abstract}
Dissertação apresentada à Escola Superior de Agricultura "Luiz de Queiroz", Universidade de São Paulo, para obtenção do título de Mestre em Agronomia, Área de Concentração: Estatística e Experimentação Agronômica.
\end{abstract}

P I R A C I C A B A

Estado de São Paulo - Brasil Julho - 2005 


\section{Errata}

\section{ALFREDO LUIZ VENZEL DE OLIVEIRA. Plano de amostragem seqüencial para o monitoramento do percevejo Lepioglossus sagma (Hemiptera: Coreidae), na cuitura da goiaba Psiditum guajava.} Figuras

1

$6 \quad 2.4$

$8 \quad 2.6$

82.6

$9 \quad 26$

$10 \quad 2.5$

$11 \quad 2.7$

$11 \quad 2.7$

$12 \quad 2.7$

12

Sormula 48

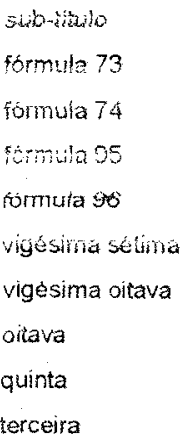

décina quarta

decima terceira

formula 41 onde se le

...com por pelo Menos...

(Pozanc ot at.)

... Nomal e a menos utilizadaknight, $1967^{1}$ )

Dessa toma Molut el al (1984).

...atraves da estatistica $\chi^{2}$ com $n-1 \ldots$

...rejeitando-se a aleatoriedade quando $\psi^{2}$ calc for maior que $x^{2}(n-1)$. rejeitando-se a aleatoniedade (Li \& Fitzpatrick, $1997)$

com $(m-1) g l$, sendo 1 .

que $m$ obsenaços forem colhetadas..

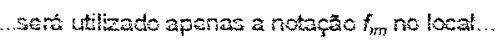

$\frac{f_{1 m}}{f_{i m}} \geq \frac{p_{0}}{p_{1}} \frac{d_{1}}{1-d_{1}}$

$\frac{f_{\mathrm{Im}}}{f_{i, m}^{\prime}} \leq \frac{p_{0}}{p_{1}} \frac{1-d_{0}}{d_{0}}$

A distribuiçäo Binomial tem.

$\log \frac{p_{1 m}}{p_{(i m}}=\sum_{i=1}^{m} y_{i} \log \frac{p_{1}}{p_{0}}+m-\sum_{i=1}^{m} y_{i} \log \frac{q_{1}}{q_{0}}$ leia-se

...com pelo Menos...

(Rozano ctal, 2003)

..Normal é a menos utilizadaknight $196 \%$

Dessa oma Mule di al (1904).

..atraves da estatistica $\chi^{2}$ com $m-1$...

...tejeitando-se a aleatoriedade quando $\chi^{2}$ cak for maior que $\alpha^{2}$, in 1) (Li \& Firparirick, 1997 ).

$\operatorname{com}(m-1) a 1$, sondo 1

que $m$ observaçzes forem coletadas.

sore utilizado aponas a notaca fin no lugar..

$\frac{f_{1 m}}{f_{0 m}} \geq \frac{p_{0}}{p_{1}} \frac{d_{1}}{\left(1-d_{1}\right)}$

$\frac{f_{l m}}{f_{t r m}} \leq \frac{p_{0}}{p_{1}} \frac{\left(1-d_{0}\right)}{d_{0}}$

Os procedinemtos são chamaús.

A distribuiça Binomial tem.

$\log \frac{p_{i m}}{p_{0 m}}=\sum_{i=1}^{m} y_{i} \log \frac{p_{i}}{p_{0}}+\left(m-\sum_{i=1}^{m} y_{i}\right) \log \frac{q_{i}}{q_{0}}$

$a_{m}=\frac{\log \frac{\beta}{1-\alpha}}{\log \frac{p_{1} q_{0}}{p_{0} q_{1}}}+m \frac{\log \frac{q_{0}}{q_{1}}}{\log \frac{p_{1} q_{0}}{p_{0} q_{1}}}$

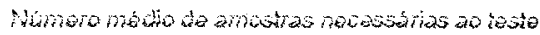

$r_{i v}=h_{i}+S m$

$r_{1}=n_{1}+5 m$

$r_{0}=h_{0}+8 m$

$r_{1}=h_{1}+5 \mathrm{~m}$

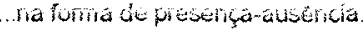

Para testar o ajuste da distribuiçåo binomial aos dados... segundo barbosa (1905), ...

Para culturas com infestaça..

Us dados de presença e ausência do percevejo... 
Dados Internacionais de Catalogação na Publicação (CIP) DIVISĀO DE BIBLIOTECA E DOCUMENTAÇÃO - ESALQ/USP

Oliveira, Alfredo Luiz Venzel de

Plano de amostragem seqüencial para o monitoramento de percevejos, Leptoglossus stigma (Hemiptera: Coreidae) na cultura da goiaba / Alfredo Luiz Venzel de Oliveira. - Piracicaba, 2005.

$62 \mathrm{p}$

Dissertação (Mestrado) - - Escola Superior de Agricultura Luiz de Queiroz, 2005.

Bibliografia.

1. Amostragem seqüencial 2. Curvas (análise matemática) 3. Distribuição binomial 4. Estatística aplicada 5. Goiaba 6. Percevejo 7. População animal - Monitoramento I. Título

$\operatorname{CDD} 595.700212$

Penitidadazopia total ou parcial deste documento, desde que citada a fonte - o autor: 


\section{DEDICATÓRIA}

\section{A \\ DEUS}

Senhor todo poderoso.

Aos meus pais,

Luiz Henrique de Oliveira e

Regina Pinato Wenzel,

fundamentais nesta conquista, pelo apoio, amor e confiança, que nortearam minha vida e me fizeram progredir.

Aos meus irmãos

Juliana Wenzel de Oliveira e

Afonso Henrique Wenzel de Oliveira

a confiança e o apoio. 


\section{AGRADECIMENTOS}

À Prof ${ }^{\underline{a}}$ Dr $^{\underline{a}}$ Sônia Maria De Stefano Piedade a orientação, a amizade e apoio, que foram fundamentais para a realização deste trabalho.

Ao Prof ${ }^{o}$ Dro ${ }^{o}$ Décio Barbin, a amizade, ensinamentos e apoio.

Aos meus pais Luiz Henrique de Oliveira e Regina Pinato Wenzel e aos meus irmãos Juliana Wenzel de Oliveira e Afonso Henrique Wenzel de Oliveira a força, o amor incondicional, a confiança e a dedicação que me deram nos momentos decisivos.

Aos amigos do mestrado e doutorado, em especial ao Willian Victor Saconato, Hélio Rubens de Carvalho Nunes, e aos amigos Melissa Lombardi Oda, Denise Viola, Júlio César Pereira, Francine Ragonha, o apoio e a compreensão.

Aos professores e funcionários do Departamento de Ciências Exatas da ESALQ/USP, que me propiciaram condições para a realização deste trabalho.

Ao pesquisador Miguel Francisco de Souza Filho do Instituto Biológico de Campinas que gentilmente cedeu os dados para a realização deste trabalho.

À Solange de Assis Paes Sabadin e Luciane Brejão do Departamento de Ciências Exatas da ESALQ/USP a paciência e atenção.

A todos que direta ou indiretamente contribuiram para a realização desse trabalho. 


\section{SUMÁRIO}

Página

LISTA DE FIGURAS . . . . . . . . . . . . . . . . . . viii

LISTA DE TABELAS . . . . . . . . . . . . . . . . . . . ix

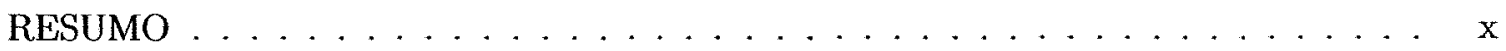

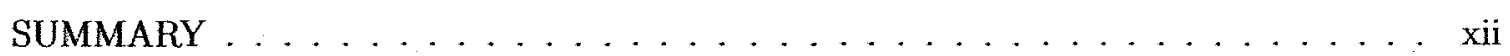

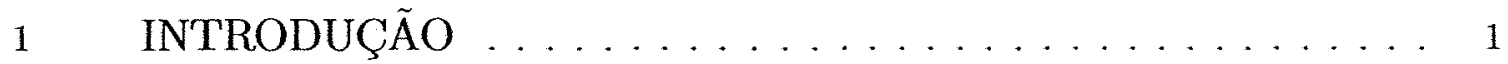

2 REVISÃO DE LITERATURA . . . . . . . . . . . 3

2.1 Amostragem Seqüencial ou Teste Seqüencial da Razão de Probabilidades . . . 3

2.2 Dificuldades na Elaboração de Planos de Amostragem Seqüenciais no Brasil . . 5

2.3 Descrição da Praga . . . . . . . . . . . . . . . . . . 5

2.4 Distribuição Espacial dos Insetos . . . . . . . . . . . . . . 5

2.5 Tamanho de Amostra . . . . . . . . . . . . . . . . 7

$2.6 \quad$ Índices de Dispersão . . . . . . . . . . . . . . . . 8

2.7 Teste Seqüencial da Razão de Probabilidades de uma Hipótese Alternativa Contra uma Hipótese Nula . . . . . . . . . . . . . . . . . . . . . 10

2.8 Função Operatória Característica do Número Médio de Amostras . . . . . . . 14

2.8.1 Dedução de uma Fórmula Geral para um Parâmetro Desconhecido . . . . . . . 14

2.9 Função do Tamanho Médio de Amostras . . . . . . . . . . . . . . . 17

2.9.1 Dedução de uma Fórmula Geral para Estabelecer um Tamanho Médio de Amostra 18

2.10 Riscos Tolerados de Tomar Decisões Erradas . . . . . . . . . . . . . . . . . 19

2.11 Métodos de Amostragem com Tamanho Fixo de Amostras . . . . . . . . . . 20

2.12 Plano de Amostragem Seqüencial para Testar a Média de uma Distribuição Binomial . . . . . . . . . . . . . . . . . . . 22

2.12 .1 Fundamentação Teórica . . . . . . . . . . . . . . . . . 22

2.12.2 Riscos Tolerados de Tomar Decisões Erradas . . . . . . . . . . . . . . . . . 24

2.12 .3 Representação Gráfica . . . . . . . . . . . . . . . . . . . 25 
2.12 .4 Obtenção da Curva Característica do Teste . . . . . . . . . . . . . 26

2.12 .5 Número Médio de Amostras Necessários ao Teste . . . . . . . . . . . . 26

2.13 Plano de Amostragem Seqüencial para Testar a Média de uma Distribuição Normal . . . . . . . . . . . . . . . . . . . . 26

2.13 .1 Fundamentação Teórica . . . . . . . . . . . . . . . . 27

2.13.2 Riscos Tolerados de Tomar Decisões Erradas . . . . . . . . . . . . . . . . . 29

2.13 .3 Determinação das Quantidades $\theta_{0}, \theta_{1}, \alpha$ e $\beta \ldots \ldots . \ldots . \ldots 29$

2.13 .4 Representação Gráfica . . . . . . . . . . . . . . . . . . . . . 31

2.13 .5 Obtenção da Curva Característica do Teste . . . . . . . . . . . . . . . 32

2.13.6 Número Médio de Amostras Necessários ao Teste . . . . . . . . . . . . . . . 33

2.14 Plano de Amostragem Seqüencial para Testar a Média de uma Distribuição de

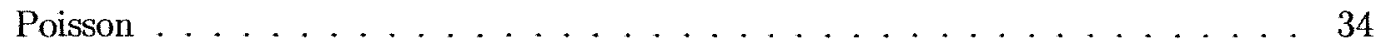

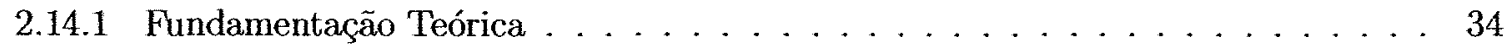

2.14.2 Riscos Tolerados de Tomar Decisões Erradas . . . . . . . . . . . . . . . . 35

2.14.3 Determinação das Quantidades $M_{0}, M_{1}, \alpha$ e $\beta \ldots \ldots$

2.14 .4 Representação Gráfica . . . . . . . . . . . . . . . . 37

2.14 .5 Obtenção da Curva Característica do Teste . . . . . . . . . . . . . 38

2.14 .6 Número Médio de Amostras Necessários ao Teste . . . . . . . . . . . . . . . . 40

2.15 Plano de Amostragem Seqüencial para Testar a Média de uma Distribuição Binomial Negativa . . . . . . . . . . . . . . . . . . . . . . . 40

2.15.1 Fundamentação Teórica . . . . . . . . . . . . . . . . . 41

2.15.2 Riscos Tolerados de Tomar Decisões Erradas . . . . . . . . . . . . . . 41

2.15.3 Determinação das Quantidades $M_{0}, M_{1}, \alpha$ e $\beta \ldots \ldots \ldots \ldots$

2.15 .4 Representação Gráfica . . . . . . . . . . . . . . . . . . . . . . . . 44

2.15 .5 Obtenção da Curva Característica do Teste . . . . . . . . . . . . . . 45

2.15.6 Número Médio de Amostras Necessários ao Teste . . . . . . . . . . . . . . . . 46

3 MATERIAL E MÉTODOS . . . . . . . . . . . . . . . . 48

$3.1 \quad$ Material . . . . . . . . . . . . . . . . . 48

3.1.1 Localização e Período de Amostragem . . . . . . . . . . . . . . . . . 48

3.2 Métodos . . . . . . . . . . . . . . . . . . . 49

3.2 .1 Monitoramento. . . . . . . . . . . . . . . . . . . . . 49

3.2 .2 Construção do Plano de Amostragem Seqüencial . . . . . . . . . . . . . . 49 


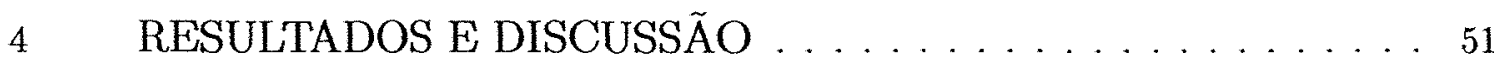

4.1 Ajuste dos Dados de Presença e Ausência a Distribuição Binomial . . . . . . . 51

4.2 Plano de Amostragem Seqüencial com Níveis de Erro Iguais a $0,20 \ldots \ldots 1$

4.3 Curva Caracteristica da Operação e Curva do Tamanho Médio de Amostras . . 56

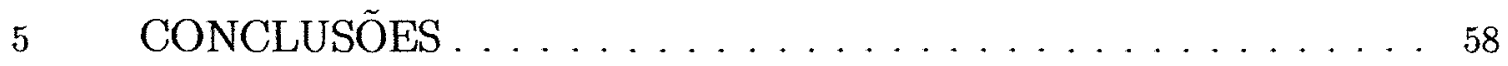

REFERÊNCIAS BIBLIOGRÁFICAS . . . . . . . . . . . . . 59 


\section{LISTA DE FIGURAS}

Página

1 Plano de Amostragem Seqüencial para o Número de Plantas Atacadas com por pelo Menos Um Percevejo Leptoglossus stigma com base na Distribuição Binomial 54

2 Curva Característica de Operação do teste de Razão de Verossimilhança para a população total de Percevejos . . . . . . . . . . . . . . . . 57

3 Curva do Tamanho Esperado de Amostras do teste Seqüêncial da Razão de Verossimilhança para a População Total de Percevejos . . . . . . . . . . . 57 


\section{LISTA DE TABELAS}

Página

1 Teste qui-quadrado de aderência das freqüências observadas às freqüências esperadas pela distribuição binomial dos dados de presença e ausência para a cultura da goiaba na região de Campinas . . . . . . . . . . . . . . . 51

2 Teste qui-quadrado de aderência das freqüências observadas às freqüências esperadas pela distribuição binomial dos dados de presença e ausência para a cultura da goiaba na região de Campinas . . . . . . . . . . . . . . . . . . . . 52

3 Teste qui-quadrado de aderência das freqüências observadas às freqüências esperadas pela distribuição binomial dos dados de presença e ausência para a cultura da goiaba na região de Campinas . . . . . . . . . . . . . . . 53

4 Plano de amostragem seqüencial para avaliar a infestação de percevejos na cultura

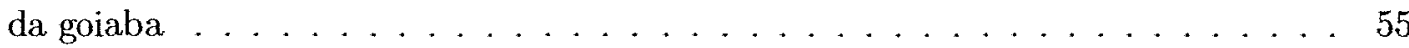




\title{
PLANO DE AMOSTRAGEM SEQÜENCIAL PARA O MONITORAMENTO DE PERCEVEJOS, LEPTOGLOSSUS STIGMA (HEMIPTERA: COREIDAE) NA CULTURA DA GOIABA
}

\author{
Autor: AlFREDO LUIZ WENZEL DE OLIVEIRA \\ Orientadora: Prof $\underline{\underline{a}}$ Dr $\underline{\underline{a}}$ SÔNIA MARIA DE STEFANO PIEDADE
}

\section{RESUMO}

Este trabalho teve como objetivo a construção de um plano de amostragem seqüencial para o percevejo (Leptoglossus stigma) na cultura da goiaba (Psidium guajava). Foram realizados estudos para atender os cultivos de goiaba de mesa da região de Campinas/SP, sendo que os dados utilizados neste trabalho foram obtidos de um estudo de levantamento de insetos-pragas e seus inimigos naturais realizado por pesquisadores do Instituto Biológico/APTA da Secretaria de Agricultura e Abastecimento para obtenção de informações a servirem de subsídio na elaboração do MIP para a cultura. Verificou-se que a distribuição binomial foi a que melhor ajustou-se aos dados de presença-ausência do Leptoglossus stigma. Foi desenvolvido um plano, com nível de erro igual a 0,20 e níveis de segurança e dano econômico de 0,10 e 0,20 , respectivamente. Foram utilizadas as fórmulas, baseadas no processo aproximado de Wald, para calcular os parâmetros das linhas de decisão e os pontos para traçar as curvas da função operatória característica e do tamanho médio das amostras para a distribuição binomial, também é apresentada uma tabela para o processo de amostragem em 
campo. Por meio dessa tabela o amostrador poderá ou não decidir com velocidade e precisão, se existe necessidade ou não de controlar a praga. 


\title{
SEQUENTIAL SAMPLING PLAN FOR MONITORING OF CHINCH-BUGS, LEPTOGLOSSUS STIGMA (HEMIPTERA: COREIDAE) IN GUAVA CROP
}

\author{
Author: ALFREDO LUIZ WENZEL DE OLIVEIRA \\ Adviser: Prof $\underline{\underline{a}}$ Dr ${ }^{\underline{a}}$ SÔNIA MARIA DE STEFANO PIEDADE
}

SUMMARY

This study has had as a goal the sequence sample plan make for the bedbug (Leptoglossus stigma) at the guava crop (Psidium guajava). Studies have been performed to assist the guava plantation around Campinas/SP, being the data applied at this study from the survey of bugs-insects and their natural predators. Researchers of the Instituto Biologico /APTA of the Secretaria de Agricultura e Abastecimento have gotten the information to support the MIP elaboration for the crop. One has checked that the binomial distribution was the one, which better adapted into the absence-presence data of Leptoglossus stigma. It has been developed a plan with an error level similar to 0,20 and economical security and damage levels from 0,10 and 0,20 respectively. The applied formula based at Wald's process to calculate the parameters of decision lines and the points in order to draw the curves of characteristic operational function and the samples average size for a binomial, also is introduced a chart for the field sample process. By this the one in charge might or not decide fast and accurately whether there is or not the necessity to control the bug 


\section{INTRODUÇÃO}

O Brasil é um dos principais produtores mundiais de goiaba (Psidium guajava L.), porém, a sua participação no mercado internacional da fruta "in natura" ainda é inexpressiva (Rozane et al.). Basicamente a produção nacional se concentra em maiores volumes nos Estados de São Paulo, Pernambuco, Bahia e Goiás (Agrianual, 2005). No Estado de São Paulo, a cultura está concentrada nas regiões de Campinas, Jaboticabal, Catanduva, Araraquara e Andradina, numa área cultivada de 6.500ha englobando cerca de 2.030 propriedades, com uma produção anual de 111 mil toneladas, segundo o Instituto Brasileiro de Geografia e Estatística (IBGE, 2002).

A cultura da goiaba no Brasil apresenta inúmeras espécies de pragas. Entretanto, levando-se em conta a sua extensão continental, clima tropical e biodiversidade exuberante, faz com que os problemas fitossanitários sejam distintos de uma região para a outra, onde quer que seja cultivada a goiabeira. Diante desse fato, verifica-se que há uma grande dificuldade em estabelecer estratégias de controle de pragas semelhantes, pois os programas de Manejo Integrado de Pragas (MIP) uma vez estabelecidos, serão distintos e adequados. para atender a realidade de cada região produtora (Souza Filho \& Costa, 2003).

Com exceção da cultura dos citros, as frutíferas tropicais, incluindo-se a goiabeira, carecem de estudos sobre: taxonomia, biologia, comportamento e ecologia das principais pragas e de seus inimigos naturais; sobre os diversos agroecossistemas formados pelas explorações frutícolas; sobre os sistemas de tomada de decisão (monitoramento e amostragem) e sobre as táticas de controle, que constituem informações essenciais para aplicação correta do MIP (Souza Filho \& Costa, 2003), pois só assim seria evitado o que ainda no momento é usual em diversas culturas de importância econômica, a aplicação desordenada de agrotóxicos baseando-se principalmente em calendários, independente de como se encontra o nível populacional da praga, trazendo conseqüências graves ao ambiente e ao próprio homem (Huffaker, 1980). 
O monitoramento populacional de pragas depende basicamente de quatro componentes que são: pessoal, mecânico, estatístico e econômico, para se chegar a uma decisão de controlar ou não uma determinada praga (Silveira Neto, 1990). Desses, o componente estatístico refere-se à precisão a ser adotada e, basicamente, está ligado a amostragem que consiste na quantificação da população presente na lavoura com vistas a tomada de decisão prática e para isso é fundamental se conhecer diversos aspectos relacionados a biologia, ecologia, dinâmica populacional, status e comportamento da praga e inimigos naturais para se obter informação precisa acerca da população (Villacorta \& Tornero, 1982; Silveira Neto, 1990; Fernandes, 2000; Norris et al., 2003).

Para implementar um plano de amostragem é preciso definir a unidade amostral, o tamanho da amostra, o tipo de caminhamento para se realizar a amostragem e a forma de amostragem a ser aplicada (Silveira Neto, 1990), porém a eficiência da mesma dependerá de alguns fatores que deverão ser levados em consideração, tais como: tamanho do campo de cultivo, valor econômico da lavoura, densidade da praga; tamanho da amostra, metas do avaliador, mobilidade da praga, precisão da amostragem e freqüência da amostragem (Norris et al., 2003).

Apesar de a amostragem fazer parte da atividade diária da maioria das pessoas em muitas áreas do conhecimento, seu uso é restrito. A conseqüência dessa atitude no campo agrícola resulta, muitas vezes, no uso indevido de produtos químicos por decisões errôneas o que acaba refletindo diretamente nos custos de produção.

Fica claro, portanto, a importância de se ter um controle eficiente, rápido e de fácil aplicação no que diz respeito à precisão do nível de infestação das culturas, considerandose um tamanho de amostra condizente, evitando com isso desperdício de tempo e recursos que acabam onerando a produção e diminuindo os lucros, principalmente em culturas de pequeno porte para as quais os recursos muitas vezes disponíveis não são tão grandes assim, além dos danos ecológicos que podem ocorrer em decorrência dessas práticas.

O objetivo do presente trabalho foi elaborar e adequar um plano de amostragem seqüencial para avaliar o nível de infestação do percevejo Leptoglossus stigma nos cultivos de goiaba de mesa da região de Campinas, SP, no interior do Estado de São Paulo. 


\section{REVISÃO DE LITERATURA}

Existem atualmente dois procedimentos de amostragem para o monitoramento de pragas na área agrícola: o comum, que se baseia num número de amostras fixas a serem colhidas por unidade de área e a seqüencial, que durante as últimas décadas, tem sido utilizada por vários estatísticos para resolução de uma série de problemas específicos, onde o número e tamanho de amostras é variável, testando uma hipótese sobre determinados parâmetros sem necessidade de estimá-los (Silveira Neto, 1990).

\subsection{Amostragem Seqüencial ou Teste Seqüencial da Razão de Probabilidades}

As primeiras idéias sobre a aplicação da amostragem seqüencial foram realizadas por Dodge \& Romig (1929) em problemas onde havia interesse em saber se a proporção de peças defeituosas num lote era alta a ponto de se rejeitar o lote ou não $\left(p<p_{0}\right)$, esse método foi chamado inicialmente de plano de amostragem duplo (Ghosh \& Sen, 1991).

Ainda segundo esses mesmos autores, em 1942 um grupo de Pesquisa em Estatística da Universidade de Columbia foi contatado pelo Departamento de Defesa Norte Americano para desenvolver métodos estatísticos para verificar e controlar a qualidade de materiais que seriam produzidos em larga escala.

Wallis e Friedman, dois estatísticos dessa universidade, debateram sobre esse problema, o objetivo era testar uma hipótese $H_{0}: f=f_{0}$ contra uma alternativa $H_{1}: f=f_{1}$ utilizando um tamanho de amostra fixo.

Esse problema levou Wallis e Friedman a uma conjectura geral da questão, que seria desenvolver um procedimento o qual fosse possível observar $y_{1}, y_{2}, \ldots, y_{m}$ sucessivamente e, não rejeitar $H_{0}$, rejeitar $H_{0}$ ou continuar a amostragem considerando as informações acumuladas com os dados. Como Wallis e Friedman não possuíam conhecimento sobre o fenômeno 
para construir um processo com regras rigorosas, eles conversaram com Wolfowitz, também estatístico da Universidade de Columbia, o qual expressou ceticismo com relação a tal técnica.

Sendo assim, Wallis e Friedman apresentaram as suas idéias a Wald em abril de 1943, o qual poucos dias depois entrou em contato com ambos, comunicando que a conjectura apresentada por eles estava, a princípio, correta.

Vários pesquisadores colaboraram para o desenvolvimento do plano de amostragem seqüencial ou, também chamado, teste da razão de probabilidades, porém Wald foi quem acabou cristalizando as idéias (Ghosh \& Sen, 1991).

De acordo com Wald (1945) para cada inteiro $m$ positivo de um espaço amostral M-dimensional ter-se-á um espaço amostral dividido em três partes mutuamente exclusivas chamadas de $R_{m}^{0}, R_{m}^{1}$ e $R_{m}$.

Após a primeira observação $y_{1}$ ter sido extraída (sorteada), a hipótese nula $H_{0}$ sob teste, por exemplo $\theta=\theta_{0}$, será aceita se $y_{1}$ pertencer ao espaço $R_{1}^{0} ; H_{0}$ será rejeitada (isto é, a hipótese alternativa será aceita, por exemplo $\theta=\theta_{1}$ ) se $y_{1}$ estiver em $R_{1}^{1}$. Caso $y_{1}$ pertença a $R_{1}$, então, uma nova observação deverá ser sorteada.

Se a terceira decisão for tomada e a segunda observação $y_{2}$ for coletada, pode ocorrer de $H_{0}$ ser aceita, $H_{1}$ ser aceita ou uma terceira observação ser coletada dependendo este fato dos pontos $\left(y_{1}, y_{2}\right)$ pertencerem a $R_{2}^{0}, R_{2}^{1}$ e $R_{2}$. Se $\left(y_{1}, y_{2}\right)$ pertencerem a $R_{2}$, uma terceira observação será coletada e uma das três decisões será tomada com base nas coordenadas $\left(y_{1}, y_{2}, y_{3}\right)$ estarem em $R_{3}^{0}, R_{3}^{1}$ e $R_{3}$ e assim sucessivamente. O processo só é parado quando, e somente quando, a primeira ou a segunda decisões forem tomadas.

Este mesmo autor afirma que em muitos casos a amostragem seqüencial necessita, em média, de um número menor de observações quando comparado com os métodos de tamanho fixo.

O número de observações exigido pela amostragem seqüencial não é pré-fixado porque em cada estágio da amostragem a decisão de suspender o processo depende do resultado acumulado das observações anteriores, sendo, portanto, uma variável aleatória.

A amostragem seqüencial é indicada quando a população está reunida na área delimitada pela cultura e a avaliação das unidades amostrais, ou seja, a verificação de existência, ou não, de danos, é feita imediatamente, sem necessitar de análises de laboratório ou outro processo mais demorado (Estefanel, 1977). 


\subsection{Dificuldades na Elaboração de Planos de Amostragem Seqüen- ciais no Brasil}

Uma das maiores dificuldades de implementação desses programas está na decisão sobre o momento de se adotar o controle, uma vez que são necessários conhecimentos de critérios de amostragem que estimem os parâmetros populacionais da praga alvo, da distribuição espacial da praga na cultura e dos danos causados à produção em função desses parâmetros (Barbosa, 1985).

Segundo Gravena, Fernandes \& Pazini (1988) um dos entraves para o desenvolvimento de planos de amostragem seqüenciais no Brasil, tem sido o tempo em que os estudos necessitam para serem desenvolvidos, implicando em prejuízos causados pela praga, custos de controle e valor da produção.

\subsection{Descrição da Praga}

Os hemípteros apresentam aparelho bucal do tipo sugador labial tetraqueta; canal de sucção e de saliva formados pela justaposição dos estiletes maxilares; normalmente dois pares de asas, o anterior em geral, totalmente ou parcialmente mais duro do que o par posterior; cercos ausentes.

$\mathrm{Na}$ subordem HETEROPTERA estão os insetos vulgarmente conhecidos por percevejos, que se caracterizam por apresentar rosto articulado. São insetos de tamanho variável, desde $1 \mathrm{~mm}$ até $100 \mathrm{~mm}$, sendo na maioria terrestres (Jacomino, 2002).

Períodos com altas temperaturas são bastante favoráveis aos insetos. Apesar de se alimentarem também das partes vegetativas, a presença de frutos é muito favorável ao aumento da população. A praga em questão ocorre o ano todo, com picos populacionais entre novembro e abril (Jacomino, 2002).

\subsection{Distribuição Espacial dos Insetos}

Para se executar uma amostragem seqüencial há necessidade de se conhecer, primeiramente, a distribuição espacial do inseto, e depois elaborar as hipóteses a serem testadas, baseando-se nos riscos de decisão para adotar, ou não, um método de controle.

Nesse sentido, Shepard \& Carner (1976) estudaram a distribuição de vários insetos que atacam a soja, durante um periodo de três anos, realizando testes de aderência 
para algumas distribuições, chegando à conclusão que a distribuição dos insetos estudados se ajusta melhor à distribuição de Poisson do que às demais.

Não há necessidade de um completo ajuste dos dados à distribuição teórica, sendo que os planos de amostragem seqüencial para insetos são, comumente elaborados, com uma das quatro distribuições teóricas seguintes: Normal, binomial, binomial negativa e Poisson, sendo que dessas, a distribuição Normal é a menos utilizada Knight, 1967 ${ }^{1}$ ) mencionado por Estefanel (1977).

Ainda, segundo Estefanel (1977), se a unidade amostral, que no caso do presente estudo é uma planta, for classificada em danificada ou não danificada e considerando-se uma população elevada, tem-se caracterizada uma distribuição binomial. Se for contado o número de insetos existentes na unidade amostral e esses insetos estiveram distribuídos ao acaso na plantação, a distribuição Normal ajustar-se-á aos dados. Se persistirem as condições citadas mas o inseto tem baixa densidade populacional a distribuição de Poisson será a mais adequada. Entretanto, como muitos insetos têm hábitos gregários, eles não estão distribuídos ao acaso na área considerada, então a distribuição binomial negativa será a que melhor se ajusta aos dados.

As disposições básicas que descrevem os arranjos espaciais ocupados pelos organismos podem ser classificadas em uma das seguintes formas: disposição aleatória, disposição uniforme e disposição agregada, sendo que cada disposição pode ser representada pelas seguintes distribuições: Poisson, binomial e binomial negativa, respectivamente, sendo que a disposição dos organismos no espaço é uma característica ecológica da espécie, resultante do nascimento, morte e migração de indivíduos (Taylor, 1984).

Segundo Barbosa (1985), em estudos usando simulações, o plano de amostragem seqüencial para presença-ausência foi menos eficiente (no sentido de tomar decisão de amostra de tamanho médio menor) quando comparado à metodologia utilizando dados de contagem sobredispersos, caracterizados por apresentarem variância maior do que a média como os que ocorrem em contagens de insetos, pragas, plantas daninhas etc, quando a dispersão foi baixa, sendo que o inverso ocorreu quando a dispersão foi alta.

Quando se tomam subunidades distribuídas aleatoriamente na área de amostragem e se registram apenas se há, ou não, incidência da característica de interesse, a distribuição resultante é, geralmente, a binomial, sendo essa técnica utilizada por entomo-

\footnotetext{
${ }^{1}$ KNIGHT, F.B. Evaluation of Forcst Insect Infestations. Annual Review of Entomology, v.12, p. 207-228, 1967.
} 
logistas (Gravena et al., 1988).

Existe um número relativamente elevado de distribuições que podem ser aplicadas nas distribuições de contágio na área de biologia e agronomia, relacionadas à distribuição espacial de ervas daninhas, insetos por área, plantas etc., sendo, porém que a distribuição binomial negativa é, segundo Perecin \& Barbosa (1992), a mais empregada na prática.

Dentre as distribuições estudadas para se determinar a distribuição espacial da lagarta do minador-dos-citros em pomares de laranjeira "Pêra-rio", concluiu-se que a binomial negativa foi a qual obteve melhor ajuste (Dantas, 2002).

\subsection{Tamanho de Amostra}

De acordo com Anscombe (1949) a melhor forma de se ajustar a contagem de insetos ou a contagem de outras populaçōes seria através da binomial negativa, sendo descrita por duas constantes, a média $m$ e um expoente $k$; acreditando, inicialmente, que para verificar o ajustamento da distribuição binomial negativa dever-se-ia ter pelo menos dez unidades amostrais.

Considerando as plantações de café no estado do Paraná, foi utilizado dois planos de amostragem seqüencial baseados em vinte e cinco e cinqüenta folhas por unidade amostral, sendo que a amostra de vinte e cinco folhas apresentou leve vantagem sobre a de cinqüenta folhas por planta (Villacorte \& Tornero, 1982).

Por sua vez, Luna et al. (1983) desenvolveram um plano de amostragem seqüencial para determinar o nível de infestação do gafanhoto na cultura da alfafa na região Oeste da Virgínia (EUA) durante um período de três anos, sendo que ocorreram sucessivas reduções ( $55 \%$ em 1980, 53\% em 1981 e $28 \%$ em 1982) em termos de número de amostras necessárias para determinação do nível de infestação dessa cultura durante o período do experimento.

Nesse mesmo sentido, Shields \& Specker (1989) desenvolveram um plano de amostragem seqüencial para determinar o nível de infestação do gafanhoto na cultura da alfafa na região Nova Yorque (EUA) comparando sua eficiência com outros três métodos de amostragem, chegando à conclusão que amostragem seqüencial apresentou uma redução de $67,7 \%$ do número de sítios que seriam necessários visitar quando comparado aos métodos de amostragem com tamanho fixo de amostra.

Devido à dificuldade em se contar o número de pragas presentes na unidade amostral, no controle da lagarta do cartucho, Spodoptera frugiperda, na cultura do milho, 
foi utilizado o método de amostragem seqüencial (presença-ausência), método esse que vem ganhando espaço importante na amostragem de pragas, pela facilidade e rapidez. A distribuição binomial calculada através da função $P(y)=k ! /[y !(k-y) !] p^{y} q^{(k-y)}$, em que $k$ ś o número máximo de pragas encontradas por unidade amostral, foi a que melhor representou a disposição do ataque da praga no campo. Foi construída uma tabela que indicava que nesse caso a tomada de decisão de se controlar, ou não, a praga só pode ser feita a partir da décima quinta amostragem; se o nível de infestação corresponde a $5 \%$ das plantas, então o tamanho esperado de amostras seria de cerca de dezessete unidades amostrais (Farias et al., 2001).

\section{6 Índices de Dispersão}

Uma série de índices de agregação ou dispersão são utilizados para medir a disposição espacial dos insetos, os quais são aplicados em estudos ecológicos ou métodos de amostragem (Young \& Young, 1998).

Dessa forma Molet et al. (1984) enumeraram as vantagens e desvantagens de diferentes índices de dispersão, concluindo que mais de um índice deve ser estimado antes que se chegue a uma conclusão a respeito da disposição espacial de uma determinada espécie de inseto.

Ainda, de acordo com Taylor (1984), o conhecimento das distribuiçôes de probabilidade que descrevem as disposiçōes de insetos (pragas) é importante para o estabelecimento dos planos de amostragem, análises estatísticas e decisão sobre o controle das pragas.

Dentre os índices mais utilizados pode-se citar: índice de Morisita $\left(I_{\delta}\right)$, parâmetro $\mathrm{K}$ da distribuição binomial negativa, razão variância/média $(I)$ e regressão da aglomeração média de Iwao (Taylor, 1984; Davis, 1993; Mollet et al., 1984; Li \& Fitzpatrick, 1997).

a) Índice de Morisita:

$$
I_{\delta}=m\left\{\frac{\left(\sum_{i=1}^{m} y_{i}^{2}-\sum_{i=1}^{m} y_{i}\right)}{\left[\left(\sum_{i=1}^{m} y_{i}\right)^{2}-\sum_{i=1}^{m} y_{i}\right]}\right\}
$$

onde $m$ é o número de unidades amostrais e $y_{i}$ o número de pragas de interesse abservadas por planta. Este índice deve ser testado através da estatística de $\chi^{2}$ com $n-1$ graus de liberdade (g.l.), sendo $I_{\delta}$ o valor do índice de dispersão. 
Se o valor de $I_{\delta}$ aproxima-se da unidade, a população é distribuída aleatoriamente (Poisson), para valores de $I_{\delta}$ menores que a unidade, a distribuição é uniforme (binomial) e para valores de $I_{\delta}$ maiores que a unidade a distribuição é agregada (binomial negativa).

O afastamento da aleatoriedade pode ser verificado através da estatística de

$$
\chi_{\delta}^{2}=I_{\delta}\left(\sum_{i=1}^{m} y_{i}-1\right)+m-\sum_{i=1}^{m} y_{i}
$$

com n-1 g.l. (Davis, 1993), rejeitando-se a aleatoriedade quando $\chi_{\text {calc }}^{2}$ for maior que $\chi_{(n-1)}^{2}$ rejeita-se a aleatoriedade (Li \& Fitzpatrick, 1997).

b) Expoente $K$ da Distribuição Binomial Negativa: Anscombe (1949) apresenta três métodos para estimar o parâmetro $k$, o primeiro método, chamado de momentos, consiste em igualar os dois primeiros momentos da distribuição às suas estimativas amostrais, resultando na seguinte expressão:

$$
k=\frac{\hat{m^{2}}}{\left(s^{2}-\hat{m}\right)} \text { ou } \frac{\overline{y^{2}}}{\left(s^{2}-\bar{y}\right)},
$$

em que $\bar{y}$ é a estimativa da média e $s^{2}$ é a estimativa do número de pragas de interesse por unidade amostral, sendo que este método ganha em eficiência quando $k 3$ maior que 1 e a média é relativamente grande.

Nesse mesmo sentido, Bliss e Fisher (1953) propõe o cálculo da estimativa de $k$ através do método da máxima verossimilhança, obtendo um valor de $k$ que iguale os dois membros da seguinte expressão:

$$
m \log \left(1+\frac{y}{\hat{k}}\right)=\frac{\sum_{i=1}^{m} A\left(y_{i}\right)}{\hat{k}+y_{i}}
$$

em que $\log 5$ o logaritmo neperiano, $\hat{k}$ a estimativa de $k, A\left(y_{i}\right)$ a soma das frequêencias das contagens que excedem a $y_{i}$ e $m$ o tamanho da amostra.

A ocorrência de um valor negativo de $k$ significa uma distribuição regular ou uniforme; quando ocorrerem valores baixos e positivos (valores de $\hat{k}<2$ ) indicam uma disposição altamente agregada; valores de $\hat{k}$ variando entre 2 e 8 representam uma distribuição moderadamente agregada e valores de $\hat{k}$ superiores a 8 uma disposição ao acaso (Southwood, 1978; Elliott, 1979).

Quando forem feitas observações em diversos locais não é aconselhável tomar a média das estimativas $\hat{k}$ de cada local para obter a estimativa $\hat{k}$ comum a todos os locais. 
c) O índice da Razão Variância / Média é dado por:

$$
I=\frac{s^{2}}{\bar{y}}
$$

onde $s^{2}$ á a variância e $\bar{y}$ é a média do número de pragas por árvore.

Um teste para esse índice pode ser feito através da estatística

$$
\chi^{2}=I(m-1)
$$

com (m-1) g.l., sendo $I$ o valor do índice de dispersão e $m$ o número de unidades amostrais.

Se $I$ aproxima-se da unidade, a população é distribuída alatoriamente, quando o valor de $I$ é maior que 1 a distribuição é agregada, por sua vez se $I$ for menor que 1 , ela será uniforme (Davis, 1993; Li \& Fitzpatrick, 1997).

d) Regressão da aglomeração média de Iwao: os coeficientes $\alpha$ e $\beta$ são estimados pela equação de regressão de $m^{*}$ sobre $\bar{m}\left(m^{*}=\alpha+\beta \bar{m}\right)$ onde $m^{*}$ ś dado pela seguinte expressão $m^{*}=\hat{m}+\left(s^{2} / \hat{m}\right)-1$. Valores de $\beta$ significantemente maiores que a unidade indicam uma distribuição agregada da população, valores iguais à unidade indicam distribuição aleatória e para valores de $\beta$ significativamente menores que a unidade a distribuição não é definida (Peña \& Baranowski, 1990).

\subsection{Teste Seqüencial da Razão de Probabilidades de uma Hipótese Alternativa Contra uma Hipótese Nula}

Seja $Y$ uma variável aleatória com função densidade de probabilidade $f\left(y_{i} ; \theta_{i}\right)$. Se $Y$ for uma variável aleatória discreta essa função $\left(y_{i} ; \theta_{i}\right), i=1,2, \ldots$ associará a cada valor de $y_{i}$ uma possibilidade de ocorrência. Por sua vez, caso $Y$ seja uma variável aleatória contínua $f\left(y_{i} ; \theta_{i}\right)$ indicará a função densidade de probabilidade (f.d.p) da variável aleatória.

Supondo que a hipótese nula a ser testada, por exemplo, $\theta=\theta_{0}$ seja verdadeira então a distribuição de $Y$ será $f\left(y ; \theta_{0}\right)$, sendo porém a hipótese alternativa verdadeira, suponhamos $\theta=\theta_{1}$ a distribuição dessa variável passa a ser $f\left(y ; \theta_{1}\right)$.

Supondo, ainda, que antes da amostra ser obtida exista a probabilidade, a priori, de $H_{0}$ ser verdadeira e que o valor dessa probabilidade seja conhecido, sendo esse valor denotado por $p_{0}$, tem-se, dessa forma, que a probabilidade, também a priori, de $H_{1}$ ser verdadeira é $p_{1}=1-p_{0}$, considerando que as hipóteses $H_{0}$ e $H_{1}$ sejam coletivamente exaustivas.

Após serem retiradas algumas observações, existirão informações adicionais que influenciarão a probabilidade que $H_{i}(\mathrm{i}=0,1)$ seja verdadeira. Seja $p_{\text {om }}$ a probabilidade a 
posteriori de $H_{0}$ ser verdadeira e $p_{1 m}$ a probabilidade a posteriori de $H_{1}$ ser verdadeira depois que $m$ observações forem colhetadas. Então, de acordo com o conhecimento da fórmula de Bayes, temos:

$$
p_{0 m}=\frac{p_{0 m} f_{0 m}\left(y_{1}, y_{2}, \ldots, y_{m}\right)}{p_{0 m} f_{0 m}\left(y_{1}, y_{2}, \ldots, y_{m}\right)+p_{1 m} f_{1 m}\left(y_{1}, y_{2}, \ldots, y_{m}\right)}
$$

e

$$
p_{1 m}=\frac{p_{1 m} f_{1 m}\left(y_{1}, y_{2}, \ldots, y_{m}\right)}{p_{0 m} f_{0 m}\left(y_{1}, y_{2}, \ldots, y_{m}\right)+p_{1 m} f_{1 m}\left(y_{1}, y_{2}, \ldots, y_{m}\right)}
$$

em que $f_{i m}\left(y_{1}, y_{2}, \ldots, y_{m}\right)$ indica a função densidade de probabilidade calculada numa amostra de espaço $m$ dimensional sob as hipóteses $H_{i}(\mathrm{i}=0,1)$. No caso de uma distribuição discreta $f_{i m}\left(y_{1}, y_{2}, \ldots, y_{m}\right)$ indicaria a probabilidade dos pontos amostrais $\left(y_{1}, y_{2}, \ldots, y_{m}\right)$ serem obtidos.

Para efeito de demonstração será utilizado apenas a notação $f_{\text {im }}$ no local de $f_{i m}\left(y_{1}, y_{2}, \ldots, y_{m}\right)$.

Sejam $d_{0}$ e $d_{1}$ dois números positivos menores que 1 e maiores que $1 / 2$. Essa restriçāo é imposta pois de outra maneira poderia ocorrer de que a hipótese com menor probabilidade a posteriori seja aceita. Supondo agora que se queira construir um teste seqüencial de tal forma que a probabilidade de tomarmos a correta decisão sob a condição de aceitar $H_{0}$ seja maior ou igual a $d_{0}$, e a probabilidade de tomarmos a correta decisão de não rejeitar a hipótese $H_{1}$ seja maior ou igual a $d_{1}$.

Dessa forma a cada estágio do processo calcula-se $p_{0 m}$ e $p_{1 m}$ e se $p_{1 m} \geq d_{1}$, não rejeita-se $H_{1}$. Se $p_{0 m} \geq d_{0}$, não rejeita-se $H_{0}$, e se $p_{1 m}<d_{1}$ ou $p_{0 m}<d_{0}$, será necessário uma nova observação. $R_{m}^{0}$ é neste processo seqüencial definido como a inequação $p_{0 m} \geq d_{0}$, $R_{m}^{1}$ é pela inequação $p_{1 m} \geq d_{1}$, e $R_{m}$ é definido simultaneamente pelas inequações $p_{1 m}<d_{1}$ e $p_{0 m}<d_{0}$. Torna-se necessário portanto que os conjuntos $R_{m}^{0}, R_{m}^{1}$ e $R_{m}$ sejam mutuamente exclusivos e coletivamente exaustivos.

Prova:

$$
p_{1 m}=\frac{p_{1} f_{1 m}}{p_{0} f_{0 m}+p_{1} f_{1 m}} \geq d_{1}
$$




$$
p_{0 m}=\frac{p_{0} f_{0 m}}{p_{0} f_{0 m}+p_{1} f_{1 m}} \geq d_{0}
$$

Que podem ser reescritas da seguinte forma:

$$
\begin{gathered}
\frac{f_{1 m}}{f_{0 m}} \geq \frac{p_{0}}{p_{1}} \frac{d_{1}}{1-d_{1}} \\
\frac{f_{1 m}}{f_{0 m}} \leq \frac{p_{0}}{p_{1}} \frac{1-d_{0}}{d_{0}}
\end{gathered}
$$

As constantes do lado direito das inequações (5) e (6) não dependem de $m$ (tamanho da amostra).

Caso não exista uma probabilidade a priori para $H_{0}$, ou ela seja desconhecida, as inequações (5) e (6) sugerem o uso do seguinte teste seqüencial: a cada estágio calcula-se $f_{1 m} / f_{0 m}$. Se $f_{1 m}=f_{0 m}=0$, o valor $f_{1 m} / f_{0 m}$ ś definido como sendo igual a 1 . Não rejeita-se $H_{1}$ se:

$$
\frac{f_{1 m}}{f_{0 m}} \geq A
$$

Não rejeita-se $H_{0}$ se:

$$
\frac{f_{1 m}}{f_{0 m}} \leq B
$$

Amostra se uma nova observação se:

$$
B<\frac{f_{1 m}}{f_{0 m}}<A
$$

Dessa forma, o número de observações necessárias para o teste é o menor valor de $m$ que satisfaça (7) ou (8). As constantes $A$ e $B$ são escolhidas de tal forma que $0<B<A$ e o teste seqüencial tenha uma probabilidade $\alpha$ de cometer o erro Tipo I e uma probabilidade $\beta$ de cometer o erro Tipo $I I$. Chama-se os procedimentos $(7)$, (8) e (9) de teste seqüencial da razão de probabilidades. 
A probabilidade de se obter uma amostra Tipo $I$ ś pelo menos $A$ vezes maior sob a hipótese $H_{1}$ do que sob a hipótese $H_{0}$. Sendo assim a medida de probabilidade de todas as amostras possíveis do Tipo $I$ também $A$ vezes maior sob $H_{1}$ do que sob $H_{0}$. A medida de probabilidade de todas as amostras possíveis do Tipo $I$ s a probabilidade de que a amostragem seqüencial termine com a não rejeição de $H_{1}$ (consequente rejeição de $H_{0}$ ). Essa probabilidade é igual a $\alpha$ quando $H_{0}$ for verdadeira e $1-\beta$ quando $H_{1}$ for verdadeira.

Obtendo-se a desigualdade $(1-\beta) \geq A \alpha$ que pode ser escrita ainda como:

$$
A \leq \frac{1-\beta}{\alpha}
$$

Da mesma maneira, a probabilidade de obter uma amostra do Tipo II sob $H_{1} \leq$ no máximo $B$ vezes maior que a probabilidade de obte-la quando $H_{0}$ for verdadeira. Então também a probabilidade de não rejeitar $H_{0}$ ś no máximo $B$ vezes maior quando $H_{1}$ for verdadeira do que quando $H_{0}$ for verdadeira, dado que a probabilidade de não rejeitar $H_{0} 3$ igual a $(1-\alpha)$ quando $H_{0}$ for verdadeira e $\beta$ quando $H_{1}$ for verdadeira, obtendo-se a desigualdade $\beta \leq B(1-\alpha)$ ou:

$$
B \geq \frac{\beta}{1-\alpha}
$$

Tem-se portanto que $(1-\beta) / \alpha$ ś um limite superior para $A$ e $\beta(1-\alpha)$ é um limite inferior para $B$.

De acordo com Wald (1947) tomando-se

$$
A=\frac{1-\beta}{\alpha}
$$

e

$$
B=\frac{\beta}{1-\alpha}
$$

a probabilidade de rejeitar $H_{0}$ quando $H_{0}$ for verdadeira (erro Tipo $I$ ) não excederá $\alpha$ e a probabilidade de aceitar $H_{0}$ quando ela for falsa (erro Tipo $I I$ ) não excederá $\beta$.

As desvantagens de transformar as desigualdades (10) e (11) em igualdades é que o tamanho da amostra pode se tornar maior antes que seja tomada alguma decisão. 


\subsection{Função Operatória Característica do Número Médio de Amostras}

Depois da obtenção de uma amostra qualquer, uma particular escolha de um conjunto $R_{m}^{0}, R_{m}^{1}$ e $R_{m}$, com $(m=1,2, \ldots)$ é feita, e a probabilidade que o processo termine com a não rejeição de uma hipótese $H_{0}$ depende apenas da distribuiçâo aleatória $Y$ sob consideração.

Antes porém, é assumido que a distribuição de $Y$ ś conhecida exceto por um número finito de parâmetros desconhecidos $\left(\theta_{1}, \theta_{2}, \ldots, \theta_{k}\right)$. Então a distribuição de $Y$ ś dada por uma função $f\left(y ; \theta_{1}, \theta_{2}, \ldots, \theta_{k}\right)$ onde a forma da função $Y$ ś conhecida, mas os verdadeiros valores dos parâmetros $\theta_{1}, \theta_{2}, \ldots, \theta_{k}$ são desconhecidos.

Desde que a distribuição de $Y$ ś determinada pelos parâmetros $\theta_{1}, \theta_{2}, \ldots, \theta_{k}$, a probabilidade de não rejeitar $H_{0}$ será uma função de $\theta$. Está função será denotada por $L(\theta)$ sendo chamada de função operatória característica.

Se existir apenas um parâmetro desconhecido $\theta$ a função $L(\theta)$ pode ser plotada com uma curva onde $\theta$ seria colocado no eixo horizontal e $L(\theta)$ no eixo vertical.

A função operatória característica está estritamente relacionada com a função poder da teoria dos testes. O poder do teste, frente a uma hipótese alternativa, é a probabilidade de rejeitar $H_{0}$ quando $H_{0} \leq$ falso. Dado que se trabalhará apenas com testes onde a probabilidade que o processo eventualmente termine é igual a 1, a probabilidade de rejeitar $H_{0}$ será, portanto, igual a $1-L(\theta)$.

\subsubsection{Dedução de uma Fórmula Geral para um Parâmetro Desconhecido}

Desde que a amostragem seqüencial para testar a hipótese $H_{0}$ contra uma hipótese alternativa $H_{1}$ seja aplicada a problemas onde o parâmetro $\theta$ pode assumir valores diferentes de $\theta_{0}$ e $\theta_{1}$, é interessante, apesar de não ser imprescindível, derivar toda a função característica $L(\theta)$.

Considere-se a expressão:

$$
\left[\frac{f\left(y, \theta_{1}\right)}{f\left(y, \theta_{0}\right)}\right]^{h(\theta)}
$$

Para cada valor de $\theta$, o valor de $h(\theta)$ é estabelecido de tal forma que $h(\theta) \neq 0$ e que sua esperança matemática seja igual a 1 , ou seja, 


$$
\int_{-\infty}^{+\infty}\left[\frac{f\left(y, \theta_{1}\right)}{f\left(y, \theta_{0}\right)}\right]^{h(\theta)} f(y, \theta) d(y)=1
$$

se $f(y, \theta)$ for uma função densidade de probabilidade, ou

$$
\sum_{y}\left[\frac{f\left(y, \theta_{1}\right)}{f\left(y, \theta_{0}\right)}\right]^{h(\theta)} f(y, \theta)=1
$$

se $Y$ for uma variável aleatória discreta, sendo o somatório considerado para todos os possíveis valores de $Y$.

Foi demonstrado por Wald (1947) que com algumas pequenas restrições na natureza da distribuição da função $f(y, \theta)$ existe exatamente um único valor $h(\theta) \neq 0$ que satisfaça plenamente (15) e (16).

Dessa forma, para qualquer valor de $\theta$, a função de $y$ dada por:

$$
f^{*}(y, \theta)\left[\frac{f\left(y, \theta_{1}\right)}{f\left(y, \theta_{0}\right)}\right]^{h(\theta)} f(y, \theta)
$$

será uma função densidade de probabilidade.

Sendo $h(\theta) \neq 0$, existem duas possibilidades para $h(\theta), h(\theta)>0$ ou $h(\theta)<0$, podendo-se dessa forma, considerar primeiro o caso em que $h(\theta)>0$.

Suponha que $H$ represente a hipótese que $f(y, \theta)$ é a verdadeira distribuição de $Y$ e $H^{*}$ represente a hipótese que $f^{*}(y, \theta)$ é a verdadeira distribuição de $Y$. Considere o teste seqüencial de razão de probabilidade $S^{*}$ para testar $H$ versus $H^{*}$. Sabe-se que enquanto:

$$
B^{h(\theta)}<\frac{f^{*}\left(y_{1}, \theta\right), f^{*}\left(y_{2}, \theta\right), \ldots, f^{*}\left(y_{m}, \theta\right)}{f\left(y_{1}, \theta\right), f\left(y_{2}, \theta\right), \ldots, f\left(y_{m}, \theta\right)}<A^{h(\theta)}
$$

deve-se continuar obtendo novas unidades amostrais.

A hipótese $H$ não será rejeitada se:

$$
\frac{f^{*}\left(y_{1}, \theta\right), f^{*}\left(y_{2}, \theta\right), \ldots, f^{*}\left(y_{m}, \theta\right)}{f\left(y_{1}, \theta\right), f\left(y_{2}, \theta\right), \ldots, f\left(y_{m}, \theta\right)} \leq B^{h(\theta)}
$$


sendo que a hipótese $H$ será rejeitada quando:

$$
\frac{f^{*}\left(y_{1}, \theta\right), f^{*}\left(y_{2}, \theta\right), \ldots, f^{*}\left(y_{m}, \theta\right)}{f\left(y_{1}, \theta\right), f\left(y_{2}, \theta\right), \ldots, f\left(y_{m}, \theta\right)} \geq A^{h(\theta)}
$$

desde que:

$$
\frac{f^{*}(y, \theta)}{f(y, \theta)}=\left[\frac{f\left(y, \theta_{1}\right)}{f\left(y, \theta_{0}\right)}\right]^{h} \theta
$$

e considerando $h(\theta)>0$, as inequações (18), (19) e (20) são equivalentes a:

$$
\begin{gathered}
B<\frac{f\left(y_{1}, \theta_{1}\right), f\left(y_{2}, \theta_{1}\right), \ldots, f\left(y_{m}, \theta_{1}\right)}{f\left(y_{1}, \theta_{0}\right), f\left(y_{2}, \theta_{0}\right), \ldots, f\left(y_{m}, \theta_{0}\right)}<A \\
\frac{f\left(y_{1}, \theta_{1}\right), f\left(y_{2}, \theta_{1}\right), \ldots, f\left(y_{m}, \theta_{1}\right)}{f\left(y_{1}, \theta_{0}\right), f\left(y_{2}, \theta_{0}\right), \ldots, f\left(y_{m}, \theta_{0}\right)} \geq A \\
\frac{f\left(y_{1}, \theta_{1}\right), f\left(y_{2}, \theta_{1}\right), \ldots, f\left(y_{m}, \theta_{1}\right)}{f\left(y_{1}, \theta_{0}\right), f\left(y_{2}, \theta_{0}\right), \ldots, f\left(y_{m}, \theta_{0}\right)} \leq B
\end{gathered}
$$

Porém essas desigualdades são idênticas a aquelas definidas no teste seqüencial da razão de probabilidades $S$ para testar uma $H_{0}$ versus $H_{1}$, quando as constantes $A$ e $B$ forem usadas. Sendo assim se o teste $S^{*}$ não rejeitar $H$ o teste $S$ leva a não rejeitar $H_{0}$, e se $S^{*}$ rejeitar $H$ o teste $S$ também conduz a rejeitar $H_{0}$. Conclui-se então que a probabilidade de não rejeitar $H_{0}$ quando $\theta$ for verdadeiro, isto é, o valor de $L(\theta)$, é a mesma probabilidade de que o teste $S^{*}$ conduza a não rejeitar $H$ quando $f(y, \theta)$ é a verdadeira distribuição de $Y$.

Considere-se $\alpha^{\prime}$ a probabilidade que $S^{*}$ leve a rejeição de $H$ quando $H$ for verdadeira, e $\beta^{\prime}$ a probabilidade de que $S^{*}$ leve a não rejeição de $H$ quando $H$ for verdadeiro. Aplicando (10) e (11) ao teste $S^{*}$ obtém-se:

$$
A^{h(\theta)} \leq \frac{1-\beta^{\prime}}{\alpha^{\prime}}
$$




$$
B^{h(\theta)} \geq \frac{\beta^{\prime}}{1-\alpha^{\prime}}
$$

No limite de encerramento do processo de amostragem temos que:

$$
A^{h(\theta)} \sim \frac{1-\beta^{\prime}}{\alpha^{\prime}}
$$

e

$$
B^{h(\theta)} \sim \frac{\beta^{\prime}}{1-\alpha^{\prime}}
$$

substituindo (28) em (27) obtem-se

$$
\alpha^{\prime} \sim \frac{1-B^{h(\theta)}}{A^{h(\theta)}-B^{h(\theta)}}
$$

mas como $\alpha^{\prime}=1-L(\theta)$, obtém-se:

$$
L(\theta) \sim \frac{A^{h(\theta)}-1}{A^{h(\theta)}-B^{h(\theta)}}
$$

Para o caso onde $L(\theta)<0$ pode-se utilizar raciocínio similar, ou seja, os resultados apresentados em (30) são válidos para o caso $L(\theta)<0$, sendo que (30) é uma fórmula aproximada posto que não foram tomados valores exatos de $A^{h(\theta)}$ e $B^{h(\theta)}$.

\subsection{Função do Tamanho Médio de Amostras}

Como foi dito anteriormente o número de observações exigidas na amostragem seqüencial não é pré-determinado, mas uma variável aleatória, pois em qualquer estágio do processo a decisão de encerrar a coleta de observações depende do resultado acumulado nas observações anteriores e, sendo uma variável aleatória possui uma média e uma variância.

Se $m$ é o número de observações necessárias para um teste seqüencial de razão de probabilidade, então $m$ é uma variável aleatória. Sendo assim, caso seja repetido o mesmo procedimento amostral continuamente, será obtido, em geral, diferentes valores de $m$, porém o interesse é no valor médio de $m$ ao longo da aplicação dessas repetidas extrações. 


\subsubsection{Dedução de uma Fórmula Geral para Estabelecer um Tamanho Médio de} Amostra

Seja $m$ o número requerido de observações pelo teste e seja $E_{m}(\theta)$ o valor esperado de $m$ quando $\theta$ for o verdadeiro valor do parâmetro. O valor esperado $E_{m}(\theta)$ é uma função de $\theta$.

Considere $M$ um inteiro suficientemente grande de tal forma que a probabilidade de que $m \geq M$ seja desprezível. Dessa forma, assumindo que $m<M$ pode-se escrever:

$$
z=z_{1}+z_{2}+\ldots+z_{M}=\left(z_{1}+z_{2}+\ldots+z_{m}\right)+\left(z_{m+1}+z_{m+2}+\ldots+z_{M}\right)
$$

em que:

$$
z_{\alpha}=\log \frac{f\left(y_{\alpha}, \theta_{1}\right)}{f\left(y_{\alpha}, \theta_{0}\right)}
$$

Calculando a esperança matemática de ambos os lados de (31), tem se que:

$$
N E(z)=E\left(z_{1}+z_{2}+\ldots+z_{m}\right)+E\left(z_{m+1}+z_{m+2}+\ldots+z_{M}\right)
$$

em que:

$$
z=\log \frac{f\left(y, \theta_{1}\right)}{f\left(y, \theta_{0}\right)}
$$

Dado que $\alpha>m$, a variável aleatória $z_{\alpha}$ ś distribuida independentemente de $m$, os valores esperados de $z_{m+1}+z_{m+2}+\ldots+z_{M}$ são iguais a $(M-m)$ vezes a esperança matemática de um valor simples $z$.

Prova:

$$
\begin{aligned}
E\left(z_{m+1}+z_{m+2}+\ldots+z_{M}\right) & =E(M-m) E(z) \\
& =M E(z)-E(m) E(z)
\end{aligned}
$$

de (33) e (35) segue que: 


$$
E\left(z_{1}+z_{2}+\ldots+z_{m}\right)-E(m) E(z)=0
$$

então, se $E(z) \neq 0$, tem-se:

$$
E(m)=\frac{E\left(z_{1}+z_{2}+\ldots+z_{m}\right)}{E(z)}
$$

se $E(z) \neq 0$.

Se $\theta$ é o verdadeiro valor do parâmetro, então $E(m)=E_{\theta}(m)$ pela definição de $E_{\theta}(m)$. Seja $E_{\theta}(z)$ o valor esperado $E(z)$ de $z$ quando $\theta:$ o verdadeiro valor do parâmetro. Então a variável aleatória $\left(z_{1}, z_{2}, \ldots, z_{m}\right)$ pode assumir somente os valores $\log A$ e $\log B$ com probabilidades $1-L(\theta)$ e $L(\theta)$, respectivamente. Dessa forma:

$$
E\left(z_{1}+z_{2}+\ldots+z_{m}\right) \sim L(\theta) \log B+[1-L(\theta)] \log A
$$

ou por meio de (37) e (38) a fórmula aproximada:

$$
E_{\theta}(m) \sim \frac{L(\theta) \log \beta+[1-L(\theta)] \log A}{E_{\theta}(z)}
$$

\subsection{Riscos Tolerados de Tomar Decisões Erradas}

Nenhum plano de amostragem pode garantir que as decisões corretas serão sempre tomadas, isso porque é sempre considerado uma parte da população em questão. Mas, como o levantamento de toda a população é muitas vezes impossível, muito dispendiosa ou destrutiva, toleram-se riscos de se tomarem decisões erradas.

Um plano de amostragem, só deve ser utilizado depois que os riscos tolerados forem devidamente estabelecidos e determinados. Dessa forma, ao decidir sobre a aplicação, ou não, de inseticidas numa lavoura, em primeiro lugar deve-se determinar o nível de infestação $\theta^{\prime}$ tal que seja economicamente vantajoso aplicar o defensivo quando o grau de infestação da lavoura $\theta$ for maior que $\theta^{\prime}$, e que não seja vantajoso aplicar o inseticida quando $\theta \leq \theta^{\prime}$. 
O parâmetro $\theta$ pode representar a proporção de unidades amostrais danificadas existentes na lavoura, no caso da distribuição binomial, ou, no caso de contagem de insetos, a média populacional de insetos existentes nas unidades amostrais.

O nível de infestação $\theta^{\prime}$ ’ função do preço do inseticida, do preço do produto colhido e do dano causado pela espécie de inseto em estudo.

Então, o problema de aplicar ou não o inseticida na lavoura pode ser formulado como o problema de testar a hipótese que $\theta \leq \theta^{\prime}$ contra a hipótese que $\theta>\theta^{\prime}$.

Se $\theta=\theta^{\prime}$ o dano causado pela praga é igual ao custo de aplicação do inseticida pouca diferença fará a decisão tomada com relação à aplicação, ou não, do inseticida. Se $\theta \leq$ consideravelmente superior a $\theta^{\prime}$ o dano causado pela praga é superior ao custo de aplicação do inseticida. Então, desaconselhar sua aplicação é um erro de conseqüências graves. Da mesma forma, se $\theta$ ś consideravelmente inferior a $\theta^{\prime}$ o dano causado pela praga é inferior ao custo de aplicação do defensivo e preconizar sua aplicação também constitui erro grave.

Logo, é possível escolher dois valores, $\theta_{0}$ inferior a $\theta^{\prime}$ e $\theta_{1}$ superior a $\theta^{\prime}$, tais que preconizar a aplicação do inseticida seja considerado erro de conseqüências práticas graves se, e somente se, $\theta \leq \theta_{0}$, e desaconselhar a aplicação seja considerado erro de conseqüências práticas graves se, e se somente, $\theta \geq \theta_{1}$. Se $\theta_{0}<\theta<\theta_{1}$ nenhuma das decisões possíveis de serem tomadas conduz a erro de conseqüências práticas desde que nesse caso o valor de $\theta$ esteja próximo do valor marginal de $\theta^{\prime}$.

Escolhidos os valores $\theta_{0}$ e $\theta_{1}$, a probabilidade de aconselhar a aplicação do inseticida quando não é necessária é pré-fixada pelo valor $\alpha\left(\theta \leq \theta_{0}\right)$ e a probabilidade de desaconselhar a aplicação quando necessária é dada pelo valor $\beta\left(\theta \geq \theta_{1}\right)$ também pré-fixado.

Dessa forma os riscos tolerados de tomar decisões erradas são fixados pelos quatro valores $\theta_{0}, \theta_{1}, \alpha$ e $\beta$. A escolha dessas quatro constantes não é um problema estatístico. Elas são escolhidas com base em considerações práticas para cada caso particular.

\subsection{Métodos de Amostragem com Tamanho Fixo de Amostras}

Com relação aos métodos que consideram um tamanho fixo de amostra e considerando que no campo agronômico a ser estudado (propriedades de pequeno porte) onde a população é finita e está reunida numa área delimitada pela cultura, uma série de procedimentos podem ser testados no caso de amostragens comuns (número de amostras fixas a serem colhidas por unidade de área) e seus resultados comparados com o método seqüencial 
(Silveira Neto, 1990).

As técnicas apresentadas a seguir são muito utilizadas, principalmente em estudos de mercado, produzindo resultados satisfatórios nessas áreas, porém de emprego praticamente nulo na área agrícola.

A amostragem aleatória simples, como o próprio nome diz, é a menos complicada de todas as técnicas. Devido às dificuldades práticas ou interesses mais elaborados, ela nem sempre é utilizada. No entanto, o seu estudo é de fundamental importância, pois ela, utilizada em conjunto com outras técnicas, pode ser muito eficaz. Como principais vantagens, requer mínimo conhecimento antecipado da população, livre de possíveis erros de classificação e facilita a análise de dados e cálculos de erros. Suas desvantagens são que o conhecimento que o pesquisador possa ter sobre o problema em estudo é desprezado e que para a mesma extensão da amostra, os erros são mais amplos do que na amostragem estratificada (Cochran, 1977).

Segundo o mesmo autor, a amostragem sistemática usa a ordem natural, selecionando-se um ponto de partida aleatoriamente e a partir daí compõe-se a armostra segundo intervalos correspondentes ao número escolhido. Como principal vantagem pode-se citar a simplicidade de colheita da amostra, permitindo fácil verificação. Já com relação às desvantagens, se o intervalo de amostragem se relaciona a uma ordenação periódica da população, pode ser introduzida variabilidade crescente; se houver efeito da estratificação, as estimativas dos erros tendem a ser altas.

Por sua vez, a amostragem estratificada proporcional, escolhe de cada unidade de amostragem, uma amostra aleatória proporcional à extensão dessa unidade. Como vantagens podem-se citar a segurança da representatividade com respeito à propriedade que serve de base para classificar as unidades, garantindo portanto, menor variabilidade do que a amostragem aleatória, e a decrescente possibilidade de não incluir elementos na população por causa do processo classificatório. Podem ser analisadas características de cada estrato e serem feitas comparações, sendo que as principais desvantagens da técnica são: sob pena de aumentar o erro, requer informação acurada acerca da proporção de população em cada estrato; se não há listas estratificadas disponíveis, prepará-las pode ser dispendioso, ocorrendo possibilidade de classificação errônea e, portanto, de aumento de variabilidade (Cochran, 1977). 


\subsection{Plano de Amostragem Seqüencial para Testar a Média de uma Distribuição Binomial}

Este problema surge, por exemplo, ao decidir sobre a aplicação ou não de inseticidas numa lavoura, cada unidade amostral é classificada em uma das categorias: danificada ou não danificada. Seja 0 o valor atribuído para unidades não danificadas e seja 1 o valor atribuído para unidades danificadas. Seja p a proporção (que é desconhecida) de unidades danificadas na lavoura. Então o resultado $y$ da inspeção de uma unidade amostral escolhida ao acaso pode tomar somente os valores 1 e 0 com probabilidade $p$ e $(1-p)$, respectivamente.

Considerando os riscos de se tomar uma decisão errada deve-se determinar um valor $p^{\prime}$ tal que a aplicação do inseticida seja desaconselhada se $p>p^{\prime}$ e não seja aconselhada se $p<p^{\prime}$. Devem-se também determinar dois valores $p_{0}$ e $p_{1}$ tais que não aconselhar a aplicação do inseticida seja um erro de conseqüências sérias se, e somente se, $p \geq p_{1}$ e preconizar o uso do inseticida seja considerado erro grave se, e somente se, $p \leq p_{0}$. O plano é delineado para testar a hipótese $p=p_{0}$ contra a hipótese $p=p_{1}$.

\subsubsection{Fundamentação Teórica}

A distribuição binomial têm função densidade de probabilidade definida por:

$$
P(Y=y)=\left(\begin{array}{c}
m \\
y
\end{array}\right) p^{y}(1-p)^{m-y}, \text { com } 0 \leq p \leq 1, y=1,2,3, \ldots, \mathrm{m}
$$

em que $m$ é o número de unidades amostrais observadas.

Se $p$ indicar a proporção de unidades amostrais infectadas na lavoura, obtida de uma amostra de $m$ elementos, a probabilidade de se obter outra amostra considerando o mesmo número de plantas danificadas e na mesma seqüencia é dada por:

$$
p_{m}=\sum_{i=1}^{m} y_{i}{ }_{q}^{m-} \sum_{i=1}^{m} y_{i}
$$

em que $\sum_{i=1}^{m} y_{i}$ é o número de unidades amostrais danificadas entre os $m$ elementos da amostra.

Sob a hipótese $p=p_{1}$ esta probabilidade torna-se 


$$
p_{1 m}=p_{1}^{m} y_{i=1}{ }_{q_{1}}^{m-} \sum_{i=1}^{m} y_{i}
$$

e sob a hipótese $p=p_{0}$

$$
p_{0 m}=p_{0}^{m} y_{i=1} q_{q_{0}}^{m-\sum_{i=1}^{m} y_{i}}
$$

A razão de probabilidade a ser calculada em cada estágio da amostragem é definida por:

$$
\frac{p_{1 m}}{p_{0 m}}=\left(\frac{p_{1}}{p_{0}}\right)_{i=1}^{m} y_{i}{\left(\frac{q_{1}}{q_{0}}\right)}^{m-\sum_{i=1}^{m} y_{i}}
$$

para facilitar os cálculos pode-se utilizar o logaritmo dessa razão de probabilidades, dessa forma:

$$
\log \frac{p_{1 m}}{p_{0 m}}=\sum_{i=1}^{m} y_{i} \log \frac{p_{1}}{p_{0}}+m-\sum_{i=1}^{m} y_{i} \log \frac{q_{1}}{q_{0}}
$$

em que $\log$ ś o logaritmo neperiano. A amostragem continua enquanto

$$
\log \frac{\beta}{1-\alpha}<\sum_{i=1}^{m} y_{i}+\left(m-\sum_{i=1}^{m} y_{i}\right) \log \frac{q_{1}}{q_{0}} \geq \log \frac{1-\beta}{\alpha}
$$

A amostragem é encerrada rejeitando-se a hipótese $p=p_{0}$ ao nível $\alpha$ de significância quando:

$$
\sum_{i=1}^{m} y_{i} \log \frac{p_{1}}{p_{0}}+\left(m-\sum_{i=1}^{m} y_{i}\right) \log \frac{q_{1}}{q_{0}} \geq \log \frac{1-\beta}{\alpha}
$$

A amostragem também é encerrada não rejeitando-se a hipótese $p=p_{0}$ com probabilidade $\beta$ de erro e não aconselhando a aplicação de inseticidas se: 


$$
\sum_{i=1}^{m} y_{i} \log \frac{p_{1}}{p_{0}}+\left(m-\sum_{i=1}^{m} y_{i}\right) \log \frac{q_{1}}{q_{0}} \leq \log \frac{1-\beta}{\alpha}
$$

Resolvendo (43) e (44) obtém-se respectivamente:

$$
\sum_{i=1}^{m} y_{i} \geq \frac{\log \frac{1-\beta}{\alpha}}{\log \frac{p_{1} q_{0}}{p_{0} q_{1}}}+m \frac{\log \frac{q_{0}}{q_{1}}}{\log \frac{p_{1} q_{0}}{p_{0} q_{1}}}
$$

e

$$
\sum_{i=1}^{m} y_{i} \leq \frac{\log \frac{1-\beta}{\alpha}}{\log \frac{p_{1} q_{0}}{p_{0} q_{1}}}+m \frac{\log \frac{q_{0}}{q_{1}}}{\log \frac{p_{1} q_{0}}{p_{0} q_{1}}}
$$

Verifica-se da desigualdades (45) e (46) que o menor e maior valor de $\sum_{i=1}^{m} y_{i}$, e que serão chamados, respectivamente, $r_{m}$ e $a_{m}$ e que permitem decidir pela não rejeição da hipótese $p=p_{1}$ e pela não rejeição da hipótese $p=p_{0}$ são:

$$
r_{m}=\frac{\log \frac{1-\beta}{\alpha}}{\log \frac{p_{100} q_{0}}{p_{0} q_{1}}}+m \frac{\log \frac{q_{0}}{q_{1}}}{\log \frac{p_{1} q_{0}}{p_{0} q_{1}}}
$$

e

$$
a_{m}=\frac{\log \frac{1-\beta}{\alpha}}{\log \frac{p_{1} q_{0}}{p_{0} q_{1}}}+m \frac{\log \frac{q_{0}}{q_{1}}}{\log \frac{p_{1} q_{0}}{p_{0} q_{1}}}
$$

\subsubsection{Riscos Tolerados de Tomar Decisões Erradas}

Como $a_{n}$ e $r_{m}$ dependem apenas de $p_{0}, p_{1}, \alpha$ e $\beta$ eles podem ser calculados para cada valor de $m$ antes de iniciar a amostragem.

Para cada tamanho $m$ de amostra, o número acumulado de unidades amostrais infectadas, ou seja, a $\sum_{i=1}^{m} y_{i}$ ś comparado com os valores $a_{m}$ e $r_{m}$. 


\subsubsection{Representação Gráfica}

A amostragem seqüencial pode ser representada graficamente. O número $m$ de observações é colocado no eixo das abscissas e o número acumulado de unidades amostrais infectadas $\sum_{i=1}^{m} y_{i}$ ś colocada no eixo das ordenadas.

O par ordenado $\left(m ; a_{m}\right)$ e $\left(m ; a_{r}\right)$ formam duas retas, chamadas de $r_{0}$ e $r_{1}$, que são traçadas antes de iniciar a amostragem, sendo que os pontos $\left(m ; \sum_{i=1}^{m} y_{i}\right)$ são representados no gráfico durante a inspeção da cultura.

Se o par ordenado $\left(m ; \sum_{i=1}^{m} y_{i}\right)$ estiver entre $R_{0}$ e $R_{1}$ continua-se colhendo unidades amostrais. Caso $\left(m ; \sum_{i=1}^{m} y_{i}\right)$ estiver em $r_{0}$ ou abaixo, não rejeita-se a hipótese $p$ $=p_{0}$ com probabilidade de erro $\beta$ e conclui-se pela não aplicação do inseticida. Se $\left(m ; \sum_{i=1}^{m} y_{i}\right)$ estiver em $r_{1}$ ou acima, rejeita-se que $p=p_{0}$ ao nível de significância $\alpha$ e decide-se pela aplicação do defensivo.

$R_{0}$ e $R_{1}$ são chamados de linha de decisão, sendo representadas pelas seguintes expressões:

$$
r_{0}=h_{0}+S m
$$

e

$$
r_{1}=h_{1}+S m
$$

onde $h_{0}$ e $h_{1}$ são coeficientes lineares, $S$ á o coeficiente angular e $m$ o número de unidades amostrais inspecionadas.

De (47) e (48) observa-se que

$$
\begin{aligned}
& h_{0}=\frac{\log \frac{\beta}{1-\alpha}}{\log \frac{p_{1} q_{0}}{p_{0} q_{1}}} \\
& h_{1}=\frac{\log \frac{1-\beta}{\alpha}}{\log \frac{p_{1} q_{0}}{p_{0} q_{1}}} \\
& S=\frac{\log \frac{q_{0}}{q_{1}}}{\log \frac{p_{1} q_{0}}{p_{0} q_{1}}}
\end{aligned}
$$




\subsubsection{Obtenção da Curva Característica do Teste}

No caso da distribuição binomial a igualdade (16) pode ser escrita como:

$$
\left(\frac{p_{1}}{p_{0}}\right)^{h(\theta)} \mathrm{p}+\left(\frac{1-p_{1}}{1-p_{0}}\right)^{h(\theta)}(1-p)=1
$$

Para construir a curva característica da operação não é necessário resolver a equação (52), pode se considerar $h=h(\theta)$ e resolvê-la em relação a $p$.

Considerando $A=\frac{1-\beta}{\alpha}$ e $B=\frac{\beta}{1-\alpha}$ e isolando o valor de $p$ tem-se:

$$
L(p)=\frac{\left(\frac{1-\beta}{\alpha}\right)^{h}-1}{\left(\frac{1-\beta}{\alpha}\right)^{h}-\left(\frac{\beta}{1-\alpha}\right)^{h}}
$$

Atribuindo-se valores pertencentes ao intervalo $[-\infty,+\infty]$ obtém-se por meio das expressões (52) e (53) respectivamente os valores $p$ e $L(p)$.

\subsubsection{Número Médio de Amostras Necessários ao Teste}

Seja a $E_{p}(m)$ definida como:

$$
E_{p}(m)=\frac{L(p)(L B-L A)+L}{p L \frac{p_{1} q_{0}}{p_{0} q_{1}}-L \frac{q_{0}}{q_{1}}}
$$

Dividindo o numerador e o denominador por $L \frac{p_{1} q_{0}}{p_{0} q_{1}}$ e confrontando com (49), (50) e (51) obtém-se:

$$
E_{p}(M)=\frac{L(p)\left(h_{0}-h_{1}\right)+h_{1}}{p-S}
$$

Colocando num gráfico diversos pontos $\left(p ; E_{\theta}(m)\right)$, obtém-se a curva do tamanho médio de amostras.

\subsection{Plano de Amostragem Seqüencial para Testar a Média de uma Distribuição Normal}

Se o número de insetos $y$ existente nas unidades amostrais for contado e os insetos estiverem distribuídos ao acaso na lavoura não sendo muito raros em relação à unidade 
amostral, e se o número de unidades amostrais for suficientemente grande, então a distribuição normal ajusta-se aos dados. Considera-se que a variável $Y$ tenha distribuição normal com média $\theta$ (desconhecida) e variância $\sigma^{2}$ (suposta conhecida), uma vez que o modelo probabilístico que descreve a distribuição da praga deve ser, preferencialmente, indexado por um único parâmetro para se aplicar o teste de Wald (1945), a qual pode ser determinada através da lei de potência de Taylor, que preconiza que a variância de uma população se relaciona com a média através de $S^{2}=a m^{b}$, onde $a$ e $b$ são coeficientes estimados por regressão linear em gráfico de escala logaritmica, ou pela transformação: $\log S^{2}=\log a+b \log m$ (Bearzoti \& Aquino, 1994).

Deve-se determinar um valor $\theta^{\prime}$ que representa o grau de infestação, ou seja, o número de insetos por unidade amostral, a partir do qual é economicamente aconselhável aplicar o inseticida, bem como dois valores $\theta_{0}$ e $\theta_{1}$ tais que não aconselhar a aplicação do inseticida seja um erro grave se, e somente se, $\theta \geq \theta_{1}$ e aconselhar sua aplicação seja considerado erro grave se, e somente se, $\theta \leq \theta_{0}$.

Conhecidos $\theta_{0}, \theta_{1}, \alpha$ e $\beta$ pode-se elaborar um plano de amostragem seqüencial para testar a hipótese $\theta=\theta_{0}$ contra a hipótese alternativa $\theta=\theta_{1}$.

\subsubsection{Fundamentação Teórica}

A distribuição normal é definida em função de dois parâmetros, a média $\theta$ e a variância $\sigma^{2}$ e tem a seguinte função densidade:

$$
f(y)=\frac{1}{\sqrt{2 \pi} \sigma} \exp ^{-\frac{(y-\theta)^{2}}{2 \sigma^{2}}}
$$

em que $-\infty<y<+\infty$.

Obtida uma amostra de tamanho $m\left(y_{1}, y_{2}, \ldots, y_{m}\right)$ a probabilidade de se obter outra amostra igual a essa é:

$$
\begin{aligned}
p_{m} & =\frac{1}{\sqrt{2 \pi} \sigma} \exp ^{-\frac{\left(y_{1}-\theta\right)^{2}}{2 \sigma^{2}}} \cdot \frac{1}{\sqrt{2 \pi} \sigma} \exp ^{-\frac{\left(y_{2}-\theta\right)^{2}}{2 \sigma^{2}}} \ldots \ldots \frac{1}{\sqrt{2 \pi} \sigma} \exp ^{-\frac{(y m-\theta)^{2}}{2 \sigma^{2}}} \\
& =\left(\frac{1}{\sqrt{2 \pi} \sigma}\right)^{m} \exp ^{-\frac{\sum_{i=1}^{m}\left(y_{i}-\theta\right)^{2}}{2 \sigma^{2}}}
\end{aligned}
$$

sob a hipótese $\theta=\theta_{0}$ tem-se: 


$$
p_{0 m}=\left(\frac{1}{\sqrt{2 \pi} \sigma}\right)^{m} \exp ^{-\frac{\sum_{i=1}^{m}\left(y_{i}-\theta_{0}\right)^{2}}{2 \sigma^{2}}}
$$

e sob a hipótese $\theta=\theta_{1}$ tem-se:

$$
p_{1 m}=\left(\frac{1}{\sqrt{2 \pi} \sigma}\right)^{m} \exp ^{-\frac{\sum_{i=1}^{m}\left(y_{i}-\theta_{1}\right)^{2}}{2 \sigma^{2}}}
$$

A razão de probabilidade a ser calculada em cada estágio da amostragem é definida por:

$$
\begin{aligned}
\frac{p_{1 m}}{p_{0 m}} & =\frac{f\left(y_{1} ; \theta_{1}\right) \cdot f\left(y_{2} ; \theta_{1}\right) \ldots f\left(y_{m} ; \theta_{1}\right)}{f\left(y_{1} ; \theta_{0}\right) \cdot f\left(y_{2} ; \theta_{0}\right) \ldots f f\left(y_{m} ; \theta_{0}\right)} \\
& =\prod_{i=1}^{m} \frac{f\left(y_{i} ; \theta_{1}\right)}{f\left(y_{i} ; \theta_{0}\right)}
\end{aligned}
$$

para facilitar os cálculos pode-se utilizar o logaritmo dessa razão de probabilidades, dessa forma:

$$
\log \frac{p_{1 m}}{p_{0 m}}=\log \frac{f\left(y_{1} ; \theta_{1}\right)}{f\left(y_{1} ; \theta_{0}\right)}+\log \frac{f\left(y_{2} ; \theta_{1}\right)}{f\left(y_{2} ; \theta_{0}\right)}+\ldots+\log \frac{f\left(y_{m} ; \theta_{1}\right)}{f\left(y_{m} ; \theta_{0}\right)}
$$

em que log ś o logaritmo neperiano, sendo assim de acordo com (43), temos:

$$
\frac{p_{1 m}}{p_{0 m}}=\frac{\exp ^{-\frac{1}{2 \sigma^{2}} \sum_{i=1}^{m}\left(y_{i}-\theta_{1}\right)^{2}}}{\exp }
$$

ou de acordo com (60):

$$
\log \frac{p_{1 m}}{p_{0 \pi n}}=\frac{\theta_{1}-\theta_{0}}{\sigma^{2}} \sum_{i=1}^{m} y_{i}+\frac{m}{2 \sigma^{2}}\left(\theta_{0}^{2}-\theta_{1}^{2}\right)
$$




\subsubsection{Riscos Tolerados de Tomar Decisões Erradas}

Se $\theta=\theta^{\prime}$, é indiferente ministrar ou não o uso de inseticidas, dessa forma é necessário estabelecer um valor de $\theta$ com domínio $\theta<\theta^{\prime}$ tal que nesse caso seja desaconselhada a aplicação do inseticida e um valor $\theta>\theta^{\prime}$ tal que, não aconselhar o uso de inseticida seja considerado um erro de conseqüências graves.

Sendo assim são necessários calcular dois valores $\theta_{0}$ e $\theta_{1}\left(\theta_{0}<\theta^{\prime}\right.$ e $\left.\theta_{1}>\theta^{\prime}\right)$ tal que a aplicação do inseticida será considerada de conseqüências graves se $\theta \leq \theta_{0}$ e o não uso será considerado de conseqüências graves se $\theta \geq \theta_{1} ;$ sendo que para valores de $\theta$ entre $\theta_{0}$ e $\theta_{1}$ não há uma decisão particular a ser tomada.

\subsubsection{Determinação das Quantidades $\theta_{0}, \theta_{1}, \alpha$ e $\beta$}

Seja $y_{1}, y_{2}, \ldots$, sucessivas observações da variável aleatória $Y$, a função densidade de probabilidade $\left(y_{1}, y_{2}, \ldots, y_{m}\right)$ é dada por:

$$
p_{0 m}=\frac{1}{(2 \pi)^{\frac{m}{2}} \sigma^{m}} \exp { }^{-\frac{1}{2 \sigma^{2}} \sum_{i=1}^{m}\left(y_{i}-\theta_{0}\right)^{2}}
$$

se $\theta=\theta_{0}$ e por:

$$
p_{1 m}=\frac{1}{(2 \pi)^{\frac{m}{2}} \sigma^{m}} \exp ^{-\frac{1}{2 \sigma^{2}} \sum_{i=1}^{m}\left(y_{i}-\theta_{1}\right)^{2}}
$$

se $\theta=\theta_{1}$.

A razão de probabilidade $p_{1 m} / p_{0 m}$ é calculada em cada estágio da inspeção, sendo tomadas novas observações enquanto:

$$
B<\frac{p_{1 m}}{p_{0 m}}=\frac{\exp }{\exp { }^{-\frac{1}{2 \sigma^{2}} \sum_{i=1}^{m}\left(y_{i}-\theta_{1}\right)^{2}} \sum_{i=1}^{m}\left(y_{i}-\theta_{0}\right)^{2}}<A
$$

A inspeção é terminada com a não aplicação de inseticidas se: 


$$
\frac{\exp ^{-\frac{1}{2 \sigma^{2}} \sum_{i=1}^{m}\left(y_{i}-\theta_{1}\right)^{2}}}{\exp ^{-\frac{1}{2 \sigma^{2}} \sum_{i=1}^{m}\left(y_{i}-\theta_{0}\right)^{2}}} \leq B
$$

e com a aplicação se:

$$
\frac{\exp ^{-\frac{1}{2 \sigma^{2}} \sum_{i=1}^{m}\left(y_{i}-\theta_{1}\right)^{2}}}{\exp ^{-\frac{1}{2 \sigma^{2}} \sum_{i=1}^{m}\left(y_{i}-\theta_{0}\right)^{2}}} \geq A
$$

os valores de $A$ e $B$ são dados por (12) e (13), respectivamente.

Aplicando o logaritmo e simplificando as inequações (65), (66) e (67) temos que:

$$
\begin{gathered}
\log \frac{\beta}{1-\alpha}<\frac{\theta_{1}-\theta_{0}}{\sigma^{2}} \sum_{i=1}^{m} y_{i}+\frac{m}{2 \sigma^{2}}\left(\theta_{0}^{2}-\theta_{1}^{2}\right)<\log \frac{1-\beta}{\alpha} \\
\frac{\theta_{1}-\theta_{0}}{\sigma^{2}} \sum_{i=1}^{m} y_{i}+\frac{m}{2 \sigma^{2}}\left(\theta_{0}^{2}-\theta_{1}^{2}\right) \leq \log \frac{\beta}{1-\alpha}
\end{gathered}
$$

e

$$
\frac{\theta_{1}-\theta_{0}}{\sigma^{2}} \sum_{i=1}^{m} y_{i}+\frac{m}{2 \sigma^{2}}\left(\theta_{0}^{2}-\theta_{1}^{2}\right) \geq \log \frac{1-\beta}{\alpha}
$$

respectivamente.

Trabalhando com as equações (68), (69) e (70), simplificando e substituindo, tem-se que, para cada unidade amostral $m$, a condição de não preconizar o uso de inseticida, isto é, não rejeitar a hipótese $\theta=\theta_{0}$, é:

$$
a_{m}=\frac{\sigma^{2}}{\theta_{1}-\theta_{0}} \log \frac{\beta}{1-\alpha}+m \frac{\theta_{0}-\theta_{1}}{2}
$$


e o valor que será chamado $r_{m}$, o qual permite tomar a decisão de rejeitar a hipótese $\theta=\theta_{0}$ e, por conseguinte, aconselhar o uso do inseticida é:

$$
r_{m}=\frac{\sigma^{2}}{\theta_{1}-\theta_{0}} \log \frac{1-\beta}{\alpha}+m \frac{\theta_{0}-\theta_{1}}{2}
$$

Essas quantidades devem ser calculadas antes de se iniciar o processo de amostragem. Ao efetuar a coleta da amostra, em cada unidade amostral inspecionada, somase o número de insetos existentes à soma do número de insetos das unidades inspecionados anteriormente, chegando-se ao valor $\sum_{i=1}^{m} y_{i}$, sendo esse valor comparado com os valores $a_{m} \mathrm{e}$ $r_{m}$ respectivos.

A investigação deve continuar enquanto $a_{m}<\sum_{i=1}^{m} y_{i}<r_{m}$. Se $a_{m} \geq \sum_{i=1}^{m} y_{i} 0$ processo é interrompido não rejeitando-se a hipótese $\theta=\theta_{0}$ com probabilidade $\beta$ de erro, não aconselhando, nesse caso, o uso de inseticidas.

Se $r_{m} \leq \sum_{i=1}^{m} y_{i}$ o processo é interrompido, rejeitando-se $\theta=\theta_{0}$ ao nível $\alpha$ de significância, e, aconselhando o uso de inseticida.

\subsubsection{Representação Gráfica}

Para se elaborar o plano de amostragem graficamente, coloca-se no eixo das abcissas o tamanho da amostra $(m)$ e no eixo das ordenadas os valores de $\sum_{i=1}^{m} y_{i}$.

As linhas de decisão têm os modelos matemáticos:

$$
r_{0}=h_{0}+S_{m}
$$

e

$$
r_{1}=h_{1}+S_{m}
$$

onde $h_{0}$ e $h_{1}$ são os coeficientes lineares e $S$ o coeficiente angular.

Das desigualdades (73) e (74) temos: 


$$
\begin{aligned}
& h_{0}=\frac{\sigma^{2}}{\theta_{1}-\theta_{0}} \log \frac{\beta}{1-\alpha}, \\
& h_{1}=\frac{\sigma^{2}}{\theta_{1}-\theta_{0}} \log \frac{1-\beta}{\alpha}
\end{aligned}
$$

e

$$
S=\frac{\theta_{0}+\theta_{1}}{2}
$$

Uma vez iniciada a amostragem seqüencial, para cada tamanho de amostra os pontos $\left(m ; \sum_{i=1}^{m} y_{i}\right)$ são plotadas no gráfico; enquanto os pontos $\left(m ; \sum_{i=1}^{m} y_{i}\right)$ estiverem entre $r_{0}$ e $r_{1}$ continua-se a amostragem. Caso o ponto $\left(m_{i} \sum_{i=1}^{m} y_{i}\right)$ estiver representado abaixo ou em $R_{0}$, com probabilidade $\beta$ de erro, não rejeita-se a hipótese de que $\theta=\theta_{0}$ e, portanto, não se aconselha o uso de inseticidas, sendo concluída a amostragem.

Por sua vez, se o ponto $\left(m ; \sum_{i=1}^{m} y_{i}\right)$ estiver acima ou em $r_{1}$, encerra-se a amostragem, rejeitando-se a hipótese $\theta=\theta_{0}$ ao nível $\alpha$ de significância, sendo aconselhado o uso de inseticidas.

\subsubsection{Obtenção da Curva Característica do Teste}

Para qualquer valor de $\theta$, indicado por $L(\theta)$, a probabilidade de que a hipótese de que não se necessita a aplicação de inseticida na lavoura é aceita. $L(\theta)$ é portanto uma função de $\theta$ chamada de curva característica do teste, quando $L(\theta)$ aproxima-se de $1, \theta$ aproxima-se de $-\infty$ e quando $\theta$ tende a $+\infty, L(\theta)$ aproxima-se de 0 . Além disso, $L(\theta)$ é uma função decrescente de $\theta$.

Normalmente conhece-se os valores de $L(\theta)$ para $\theta=\theta_{0}$ e $\theta=\theta_{1}$, sendo que um método prático para o cálculo de $L(\theta)$ foi apresentado por Wald (1945) sendo descrito a seguir:

Se $\left(\theta_{1}-\theta_{0}\right) / \sigma$ é muito pequeno, pode-se usar na prática, uma boa aproximação para $L(\theta)$ através da expressão: 


$$
L(\theta) \sim 1-\frac{1-\left(\frac{\beta}{1-\alpha}\right)^{h}}{\left(\frac{1-\beta}{\alpha}\right)^{h}-\left(\frac{\beta}{1-\alpha}\right)^{h}}=\frac{\left(\frac{1-\beta}{\alpha}\right)^{h}-1}{\left(\frac{1-\beta}{\alpha}\right)^{h}-\left(\frac{\beta}{1-\alpha}\right)^{h}}
$$

onde $h$ é obtida, primeiramente, calculando-se a função característica $\varphi(t)$ da variável:

$$
z=\log \frac{\exp ^{\frac{-1}{2 \sigma^{2}}\left(y-\theta_{1}\right)^{2}}}{\exp ^{-\frac{1}{2 \sigma^{2}}\left(y-\theta_{0}\right)^{2}}}=\frac{1}{2 \sigma^{2}}\left[2\left(\theta_{1}-\theta_{0}\right) y+\theta_{0}^{2}-\theta_{1}^{2}\right]
$$

Tem-se que $z \grave{s}$ normalmente distribuída com média $\frac{\theta_{0}^{2}-\theta_{2}^{2}}{2 \sigma^{2}}+\frac{\left(\theta_{1}-\theta_{0}\right)^{\theta}}{\sigma^{2}}$ e variância igual a $\frac{\left(\theta_{1}-\theta_{0}\right)^{2}}{\sigma^{2}}$, consequentemente $\varphi(t)$ é dado por:

$$
\varphi(t)=\exp \left[\frac{\theta_{0}^{2}-\theta_{1}^{2}}{2 \sigma^{2}}+\frac{\left(\theta_{1}-\theta_{0}\right)^{\theta}}{\sigma^{2}}\right] t+\frac{\left(\theta_{1}-\theta_{0}\right)^{2} t^{2}}{2 \sigma^{2}}
$$

O valor $h$ é uma raíz real não nula obtida através da relação $\varphi(t)=1$, então:

$$
h=\frac{\left(\theta_{1}^{2}-\theta_{0}^{2}\right)-2\left(\theta_{1}-\theta_{0}\right)^{\theta}}{\left(\theta_{1}-\theta_{0}\right)^{2}}=\frac{\theta_{1}+\theta_{0}-2 \theta}{\theta_{1}-\theta_{0}}
$$

A curva característica pode então ser obtida através da expressão (80) substituindo valor de $h$ pelo resultado da expressão (81).

\subsubsection{Número Médio de Amostras Necessários ao Teste}

Seja a $E_{\theta}(m)$ o valor esperado do número de observaçōes necessárias para o teste quando $\theta$ for a verdadeira média de $Y$.

Dessa forma, segundo Wald (1945), uma boa aproximação para o valor $E_{\theta}(m)$ śdado por:

$$
E_{\theta}(m) \sim 2 \sigma^{2}\left(\frac{L(\theta) \log \frac{\beta}{1-\alpha}+(1-L(\theta)) \log \frac{1-\beta}{\alpha}}{\theta_{0}^{2}-\theta_{1}^{2}+2\left(\theta_{1}-\theta_{0}\right) \theta}\right)
$$

em que $L(\theta)$ é dado por (78).

Existem situações raras, em que o número de observações atingidas é três vezes maior que o valor esperado antes do teste ser encerrado, dessa forma, pode-se truncar o teste neste estágio sem afetar seriamente a probabilidade de tomar uma decisão errada. 


\subsection{Plano de Amostragem Seqüencial para Testar a Média de uma Distribuição de Poisson}

Se a espécie estudada tem distribuição ao acaso na lavoura e se o inseto é raro em relação à unidade amostral utilizada, a variável $Y$, correspondente aos dados de contagem do número de insetos existentes nas diversas unidades amostrais, possivelmente segue distribuição de Poisson.

Deve-se determinar o valor $M^{\prime}$ que corresponde à média de insetos por unidade amostral a partir da qual as medidas de controle seriam economicamente aconselháveis. Aplicações de inseticidas não seriam executadas se a média de insetos por unidade amostral existente na lavoura fosse menor ou igual a $M^{\prime}$ (média de insetos por unidade amostral a partir da qual devem-se tomar medidas de controle).

Devem-se fixar também dois valores $M_{0}$ e $M_{1}$, sendo $M_{0}<M^{\prime}$ e $M_{1}>M^{\prime}$, tais que, rejeitar a hipótese $M=M_{0}$ e então preconizar o uso de inseticida, seja considerado erro grave se, e somente se, $M<M_{0}$, e aceitar a hipótese $M=M_{0}$ não aconselhando o uso de inseticida seja erro grave se, e somente se, $M>M_{1}$.

Fixados $M_{0}, M_{1}, \alpha$ e $\beta$ podem-se desenvolver as fórmulas para o plano de amostragem seqüencial para testar a hipótese $M=M_{0}$ contra a hipótese alternativa $M=$ $M_{1}$.

\subsubsection{Fundamentação Teórica}

A distribuição de Poisson é caracterizada por um único parâmetro, a média $M$, a qual é igual à variância.

A função de probabilidade de uma Poisson é:

$$
P(Y=y)=e^{-M} \frac{M^{y}}{y !}
$$

em que $M>0$ e $y=1,2,3, \ldots$, corresponde ao número de insetos encontrados nas unidades amostrais.

Extraída uma amostra $\left(y_{1}, y_{2}, \ldots, y_{m}\right)$ a probabilidade de se retirar uma outra amostra igual a anterior é dada por: 


$$
\begin{aligned}
p_{m} & =e^{-M} \frac{M_{1}^{y}}{y_{1} !} \cdot e^{-M} \frac{M_{2}^{y}}{y_{2} !} \ldots e^{-M} \frac{M_{m}^{y}}{y_{m} !} \\
& =e^{-m M} \frac{\sum_{i=1}^{m} y_{i}}{y_{1} ! y_{2} ! \ldots y_{m} !}
\end{aligned}
$$

sob a hipótese $M=M_{0}$, tem-se:

$$
p_{0 m}=e^{-m M_{0}} \frac{\sum_{i=1}^{m} y_{i}}{y_{1} ! . y_{2} ! \ldots . y_{m} !}
$$

sob a hipótese $M=M_{1}$, tem-se:

$$
p_{1 m}=e^{-m M_{1}} \frac{\sum_{i=1}^{m} y_{i}}{y_{1} ! . y_{2} ! \ldots y_{m} !}
$$

De acordo com (43) tem-se que a razão de probabilidade é:

$$
\frac{p_{1 m}}{p_{0 m}}=\frac{e^{-m M_{1}} M_{1}^{i=1} y_{i}}{\sum^{m} y_{i}}=\frac{e^{-m M_{1}}}{e^{-m M_{0}}}\left(\frac{M_{1}}{M_{0}}\right)^{\sum_{i=1}^{m} y_{i}}
$$

ou utilizando a escala logaritmica onde $\log$ ś o logaritmo neperiano:

$$
\log \frac{p_{1 m}}{p_{0 m}}=-m\left(M_{1}-M_{0}\right)+\sum_{i=1}^{m} y_{i}\left(\log M_{1}-\log M_{0}\right)
$$

\subsubsection{Riscos Tolerados de Tomar Decisões Erradas}

Se $M=M^{\prime}$, é indiferente ministrar ou não o uso de inseticidas, dessa forma é necessário estabelecer um valor de $M$ com domínio $M<M^{\prime}$ tal que nesse caso seja desaconselhado a aplicação do inseticida e um valor $M>M^{\prime}$ tal que, não aconselhar o uso de inseticida seja considerado um erro de conseqüências graves. 
Sendo assim são necessários calcular dois valores $M_{0}$ e $M_{1}\left(M_{0}<M^{\prime}\right.$ e $M_{1}>$ $M^{\prime}$ ) tal que a aplicação do inseticida será considerada de conseqüências graves se $M \leq M_{0} \mathrm{e}$ o não uso será considerado de conseqüências graves se $M \geq M_{1}$; sendo que para valores de $M$ entre $M_{0}$ e $M_{1}$ não há uma decisão particular a ser tomada.

\subsubsection{Determinação das Quantidades $M_{0}, M_{1}, \alpha$ e $\beta$}

A partir das fórmulas apresentadas, observa-se que a amostragem continua até que:

$$
\log \frac{\beta}{1-\alpha}<-m\left(M_{1}-M_{0}\right)+\sum_{i=1}^{m} y_{i}\left(\log M_{1}-\log M_{0}\right)<\log \frac{1-\beta}{\alpha}
$$

A amostragem é encerrada, rejetando-se a hipótese $M=M_{0}$ ao nível $\alpha$ de significância, e, nesse caso, aconselhando a aplicação de inseticidas se:

$$
-m\left(M_{1}-M_{0}\right)+\sum_{i=1}^{m} y_{i}\left(\log M_{1}-\log M_{0}\right) \geq \log \frac{1-\beta}{\alpha}
$$

ou também sendo encerrada não rejeitando a hipótese $M=M_{0}$ com probabilidade $\beta$ de erro, ou não aconselhando o uso de inseticida, se:

$$
-m\left(M_{1}-M_{0}\right)+\sum_{i=1}^{m} y_{i}\left(\log M_{1}-\log M_{0}\right) \leq \log \frac{\beta}{1-\alpha}
$$

Isolando o valor de $\sum_{i=1}^{m} y_{i}$ nas desigualdades (87) e (88) tem-se:

$$
\begin{aligned}
\sum_{i=1}^{m} y_{i} & \geq \frac{\log \frac{1-\beta}{\alpha}}{\log M_{1}-\log M_{0}}+m \frac{M_{1}-M_{0}}{\log M_{1}-\log M_{0}} \\
\sum_{i=1}^{m} y_{i} & \leq \frac{\log \frac{\beta}{1-\alpha}}{\log M_{1}-\log M_{0}}+m \frac{M_{1}-M_{0}}{\log M_{1}-\log M_{0}}
\end{aligned}
$$

Na expressão (92) verifica-se que o maior valor de $\sum_{i=1}^{m} y_{i}$ chamado de $a_{m}$, possibilita terminar a amostragem com a não rejeição da hipótese $M^{i=1}=M_{0}$ e, consequentemente, não aconselhar o uso de inseticida é: 


$$
a_{m}=\frac{\log \frac{\beta}{1-\alpha}}{\log M_{1}-\log M_{0}}+m \frac{M_{1}-M_{0}}{\log M_{1}-\log M_{0}}
$$

Da mesma maneira, examinando (91) verifica-se que o menor valor de $\sum_{i=1}^{m} y_{i}$ que permite terminar a amostragem, rejeitando-se a hipótese $M=M_{0}$ e portanto aconselhando o uso de inseticidas, e que será chamado de $r_{m}$ s:

$$
r_{m}=\frac{\log \frac{1-\beta}{\alpha}}{\log M_{1}-\log M_{0}}+m \frac{M_{1}-M_{0}}{\log M_{1}-\log M_{0}}
$$

As quantidades $a_{m}$ e $r_{m}$ são calculados antes de se iniciar a amostragem. Para cada unidade amostral examinada calcula-se $\sum_{i=1}^{m} y_{i}$ que é o número acumulado de insetos encontrados até a unidade amostral em questão, comparando-se esses valores com os respectivos $a_{m}$ e $r_{m}$ relativos ao tamanho da amostra envolvidos nessa etapa.

Se $a_{m}<\sum_{i=1}^{m} y_{i}<r_{m}$ deve-se continuar a amostragem. Se $a_{m} \geq \sum_{i=1}^{m} y_{i}$ o processo 3́ interrompido não rejeitando-se a hipótese $M=M_{0}$ com probabilidade $\beta$ de erro, e, não aconselhando o uso de inseticidas.

Caso $r_{m} \leq \sum_{i=1}^{m} y_{i}$ o processo também é interrompido, rejeitando-se a hipótese $M=M_{0}$ ao nível $\alpha$ de significância, e, preconizando o uso de inseticida.

\subsubsection{Representação Gráfica}

Para se realizar o plano de amostragem graficamente, coloca-se no eixo das abcissas o tamanho da amostra $m$ e no eixo das ordenadas os valores de $\sum_{i=1}^{m} y_{i}$, dessa forma as coordenadas $\left(a_{m} ; \sum_{i=1}^{m} y_{i}\right)$ formam a linha de rejeição $r_{0}$ e as coordenadas $\left(r_{m} ; \sum_{i=1}^{m} y_{i}\right)$ formam as linhas de rejeição $r_{1}$.

Matematicamente as linhas de rejeição são descritas da seguinte forma:

$$
r_{0}=h_{0}+S_{m}
$$

e

$$
r_{1}=h_{1}+S_{m}
$$


onde $h_{0}$ e $h_{1}$ são os coeficientes lineares e $S$ o coeficiente angular.

Das desigualdades (95) e (96) temos:

$$
\begin{aligned}
& h_{0}=\frac{\log \frac{\beta}{1-\alpha}}{\log M_{1}-\log M_{0}}, \\
& h_{1}=\frac{\log \frac{1-\beta}{\alpha}}{\log M_{1}-\log M_{0}}
\end{aligned}
$$

e

$$
S=\frac{M_{1}+M_{0}}{\log M_{1}-\log M_{0}}
$$

A cada unidade amostral observada as coordenadas $\left(m ; \sum_{i=1}^{m} y_{i}\right)$ são representadas no gráfico. Enquanto esses pontos estiverem entre as duas linhas de decisão, novas unidades amostrais devem ser examinadas.

Quando porém, o par $\left(m ; \sum_{i=1}^{m} y_{i}\right)$ situar-se em $r_{0}$ ou abaixo dele, a amostragem sterminada não rejeitando-se a hipótese $M=M_{0}$ com probabilidade de erro igual a $\beta$, e dessa forma, não aconselhando o uso de indeticida. Caso $\left(m ; \sum_{i=1}^{m} y_{i}\right)$ se situar em $r_{1}$ ou acima dela a amostragem também é encerrada, rejeitando $H_{0}$, ao nível $\alpha$ de significância, isto é, preconizando a aplicação do inseticida.

\subsubsection{Obtenção da Curva Característica do Teste}

Tem-se que a função densidade de probabilidade da Poisson é:

$$
P(Y=y)=e^{-M} \frac{M^{y}}{y !}
$$

de (16) temos que:

$$
\sum_{y=0}^{\infty}\left[\frac{e^{-M_{1}} M_{1}^{y}}{e^{-M_{0}} M_{0}^{y}}\right]^{h(M)} e^{-M} \frac{M^{y}}{y !}=1
$$


ou

$$
e^{M 0 h(M)-M_{1} h(M)-M} \sum_{y=0}^{\infty} \frac{\left(M_{1}^{h(M)} M_{0}^{-h(M)} M\right)^{y}}{y !}=1
$$

desenvolvendo o somatório pela série de McLaurin e comparando com a expressão $e^{z}$, verifica-se que:

$$
\sum_{y=0}^{\infty} \frac{\left(M_{1}^{h(M)} M_{0}^{-h(M)} M\right)^{y}}{y !}=e^{M_{1} h(M)-M_{0} h(M)-M}
$$

substituindo em (101):

$$
e^{M_{0} h(M)-M_{1} h(M)-M} e^{M_{1}^{h(M)} M_{0}^{-h(M)} M}=1
$$

Aplicando logaritmos em (103) tem-se:

$$
M_{0} h(M)-M_{1} h(M)-M+M_{1}^{h(M)}+M_{0}^{-h(M)}+M=0
$$

Fazendo $h(M)=h$ e resolvendo em relação a $M$ chega-se a:

$$
M=\frac{h\left(M_{1}-M_{0}\right)}{M_{1}^{h} M_{0}^{-h}-1}
$$

Tomando-se $A=\frac{\beta-1}{\alpha}$ e $B=\frac{\beta}{1-\alpha}$ a expressão (30) torna-se:

$$
L(M)=\frac{\left(\frac{1-\beta}{\alpha}\right)^{h}-1}{\left(\frac{1-\beta}{\alpha}\right)^{h}-\left(\frac{\beta}{1-\alpha}\right)^{h}}
$$

Atribuindo-se valores arbitrários a $h$ em (105) e (106) obtém-se $M$ e $L(M)$, os quais ao serem inseridos num gráfico permitem traçar a curva da função característica da operação. 


\subsubsection{Número Médio de Amostras Necessários ao Teste}

Seja a seguinte função densidadde probabilidade da Poisson:

$$
P(Y=y)=e^{-M} \frac{M^{y}}{y !}
$$

em que $M>0$ e $y=1,2,3, \ldots$

Então de acordo com a seção 3.9.1, tem-se:

$z=\log \frac{f\left(y ; M_{1}\right)}{f\left(y ; M_{0}\right)}=\log \frac{e^{-M_{1}} M_{1}^{y}}{e^{-M_{0}} M_{0}^{y}}=\log \left(e^{M_{0}-M_{1}} M_{1}^{y} M_{0}^{-y}\right)=M_{0}-M_{1}+y\left(\log M_{1}-\log M_{0}\right)$

Seja $E_{M}(z)$ o valor esperado de $z$ quando $M$ for a verdadeira média de $Y$, então:

$$
E_{M}(z)=M_{0}-M_{1}+M\left(\log M_{1}-\log M_{0}\right)
$$

Substituindo-se o valor de $E_{M}(Z)$ em (39) tem-se:

$$
E_{M}(m)=\frac{L(M)(\log B-\log A)+\log A}{M_{0}-M_{1}+M\left(\log M_{1}-\log M_{0}\right)}
$$

Dividindo o numerador e o denominador por $\left(\log M_{1}-\log M_{0}\right)$ e comparando com (97), (98) e (99) chega-se:

$$
E_{M}(m)=\frac{L(M)\left(h_{0}-h_{1}\right)+h_{1}}{M-S}
$$

Para traçar a curva do tamanho médio das amostras deve-se inicialmente calcular os valores $M$ e $L(M)$ com auxílio das expressões (105) e (106), atribuindo-se valores arbitrários a $h$.

\subsection{Plano de Amostragem Seqüencial para Testar a Média de uma Distribuição Binomial Negativa}

Muitos insetos têm a tendência de formar conglomerados, não estando distribuídos ao acaso na lavoura. A causa da existência desses agrupamentos pode ser a forma da desova e conseqüente nascimento de insetos em grupos, ou o agrupamento posterior em pontos onde o ambiente é mais favorável ou o alimento mais abundante. Em geral, a distribuição binomial negativa se ajusta a dados de contagem com essa característica. 


\subsubsection{Fundamentação Teórica}

A distribuição binomial negativa é descrita por dois parâmetros a média $M$ e o expoente $k$ que está veiculado à dispersão da variável e sua forma geral é:

$$
f(y)=\left(\begin{array}{c}
k+y-1 \\
y
\end{array}\right)\left(\frac{M}{k+M}\right)^{y}\left(1+\frac{M}{k}\right)^{-k}
$$

em que $M \geq 0$ e $k>0$

Anscombe (1949) relata que existem evidências teóricas de que o parâmetro $k$ depende de fatores intrínsecos da espécie, enquanto que a média $M$ depende de fatores ambientais. Assim, dados de contagem de insetos provenientes de diversos locais teriam aproximadamente o mesmo $k$, embora com médias diferentes.

\subsubsection{Riscos Tolerados de Tomar Decisões Erradas}

Da mesma forma que foi visto para outras distribuições, deve-se inicialmente estabelecer o valor $M^{\prime}$ que é a média de insetos por unidade amostral a partir da qual a adoção de medidas de controle é economicamente viável. Então, seriam usados defensivos somente se a média $M$ do número de insetos por unidade amostral fosse superior a $M^{\prime}$.

É necessário, também, estabelecer outros dois fatores $M_{0}$ e $M_{1}$, o primeiro menor e o segundo maior do que $M^{\prime}$. A escolha deve ser feita de tal modo que não indicar a aplicação de inseticida seja considerado erro grave se, e somente se, $M \leq M_{1}$, e aconselhar o uso de controle químico seja considerado erro grave se, e somente se, $M \geq M_{0}$.

\subsubsection{Determinação das Quantidades $M_{0}, M_{1}, \alpha$ e $\beta$}

O teste seqüencial da razão de probabilidades permite estabelecer um plano de tal forma que aconselhar a aplicação de controle químico não exceda um valor $\alpha$ quando $M$ $\leq M_{0}$ e a possibilidade de não preconizar o uso de inseticidas não seja maior que $\beta$ quando $M \geq M_{0}$.

O teste seqüencial da razão de probabilidade é usado para testar a hipótese $M=M_{0}$ contra a hipótese $M=M_{1}$. Inicialmente devem ser calculados os valores $p_{0}, p_{1}, q_{0}$ e $q_{1}$, onde $p=M / k$ e $q=1+p$, a partir de $M_{0}$ e $M_{1}$.

Sendo assim a probabilidade de obter um número $y$ de insetos na contagem de 
uma unidade amostral é dada pela função de probabilidade da distribuição Bliss \& Fisher ${ }^{2}$ ) mencionado por Estefanel (1977):

$$
f(y)=\frac{(k+y-1) !}{y !(k-1) !} \cdot \frac{p^{y}}{q^{k+y}}
$$

em que $\mathrm{y}=0,1,2, \ldots$

A probabilidade de obter uma amostra de tamanho $m$ dessa distribuição de probabilidade é:

$$
p_{m}=\frac{\left(k+y_{1}-1\right) !}{y_{1} !(k-1) !} \cdot \frac{\left(k+y_{2}-1\right) !}{y_{2} !(k-1) !} \ldots \frac{\left(k+y_{m}-1\right) !}{y_{m} !(k-1) !} \cdot \frac{\sum^{y=1} y_{i}^{m}}{q k+\sum_{y=1}^{m} y_{i}}
$$

Como os dados do problema são referentes a apenas uma das dezoito propriedades rurais que fazem parte do programa de Manejo Intergrado de Pragas, não há necessidade de se estimar um $k$ comum a todas as propriedades sendo assim, para as hipóteses $M=M_{1}$ versus $M=M_{0}$, têm-se:

$$
p_{0 m}=\frac{\left(k+y_{1}-1\right) !}{y_{1} !(k-1) !} \cdot \frac{\left(k+y_{2}-1\right) !}{y_{2} !(k-1) !} \cdots \frac{\left(k+y_{m}-1\right) !}{y_{m} !(k-1) !} \cdot \frac{\sum_{0}^{m} y_{i}}{q_{0}{ }^{m k+1} \sum_{y=1}^{m} y_{i}}
$$

e

$$
p_{1 m}=\frac{\left(k+y_{1}-1\right) !}{y_{1} !(k-1) !} \cdot \frac{\left(k+y_{2}-1\right) !}{y_{2} !(k-1) !} \ldots \frac{\left(k+y_{m}-1\right) !}{y_{m} !(k-1) !} \cdot \frac{\sum_{y=1}^{m} y_{i}}{p_{1}{ }^{m}+\sum_{y=1}^{m} y_{i}}
$$

\footnotetext{
${ }^{2}$ BLISS, C. I.; FISHER, R. A. Fitting the binomial distribution to biological data. Biometrics, v. 9, p. $176-200,1953$.
} 
Dessa maneira de acordo com (59) a razão de probabilidade é expressa da seguinte forma:

$$
\frac{p_{1 m}}{p_{0 m}}=\left(\frac{p_{1}}{p_{0}}\right)^{\sum_{y=1}^{m} y_{i}} \cdot\left(\frac{q_{0}}{q_{1}}\right)^{m k} \cdot\left(\frac{q_{0}}{q_{1}}\right)^{\sum_{y=1}^{m} y_{i}}
$$

ou sob a forma logaritmica:

$$
\log \frac{p_{1 m}}{p_{0 m}}=\sum_{i=1}^{m} y_{i} \log \left(\frac{p_{1}}{p_{0}}\right)+m k \log \left(\frac{q_{0}}{q_{1}}\right)+\sum_{i=1}^{m} y_{i} \log \left(\frac{q_{0}}{q_{1}}\right)
$$

Tem-se que a amostragem continua até:

$$
\log \frac{\beta}{1-\alpha}<\sum_{i=1}^{m} y_{i} \log \left(\frac{p_{1}}{p_{0}}\right)+m k \log \left(\frac{q_{0}}{q_{1}}\right)+\sum_{i=1}^{m} y_{i} \log \left(\frac{q_{0}}{q_{1}}\right)<\log \frac{1-\beta}{\alpha}
$$

A amostragem é encerrada se:

$$
\sum_{i=1}^{m} y_{i} \log \left(\frac{p_{1}}{p_{0}}\right)+m k \log \left(\frac{q_{0}}{q_{1}}\right)+\sum_{i=1}^{m} y_{i} \log \left(\frac{q_{0}}{q_{1}}\right) \geq \log \frac{1-\beta}{\alpha}
$$

rejeitando-se a hipótese $M=M_{0}$ e aconselhando-se o uso de inseticida, se:

$$
\sum_{i=1}^{m} y_{i} \log \left(\frac{p_{1}}{p_{0}}\right)+m k \log \left(\frac{q_{0}}{q_{1}}\right)+\sum_{i=1}^{m} y_{i} \log \left(\frac{q_{0}}{q_{1}}\right) \leq \log \frac{\beta}{1-\alpha}
$$

não rejeita-se a hipótese $M=M_{0}$ com a probabilidade $\beta$ de erro, não aconselhando, neste caso, o uso de inseticidas.

$$
\begin{aligned}
& \text { Isolando-se } \sum_{i=1}^{m} y_{i} \text { em (113) e (114) tem-se: } \\
& \sum_{i=1}^{m} y_{i} \geq \frac{\log \left(\frac{1-\beta}{\alpha}\right)}{\log \left(\frac{p_{1} q_{0}}{p_{0} q_{1}}\right)}+m k \frac{\log \left(\frac{q_{1}}{q_{0}}\right)}{\log \left(\frac{p_{1} q_{0}}{p_{0} q_{1}}\right)}
\end{aligned}
$$




$$
\sum_{i=1}^{m} y_{i} \leq \frac{\log \left(\frac{\beta}{1-\alpha}\right)}{\log \left(\frac{p_{1} q_{0}}{p_{0} q_{1}}\right)}+m k \frac{\log \left(\frac{q_{1}}{q_{0}}\right)}{\log \left(\frac{p_{1} q_{0}}{p_{0} q_{1}}\right)}
$$

De acordo com (115) verifica-se que o menor valor de $\sum_{i=1}^{m} y_{i}$, que será chamado $r_{m}$, que permite preconizar o uso de inseticida, ou seja, o valor que permite rejeitar a hipótese $M=M_{0}$ :

$$
r_{m}=\frac{\log \left(\frac{1-\beta}{\alpha}\right)}{\log \left(\frac{p_{1} q_{0}}{p_{0} q_{1}}\right)}+m k \frac{\log \left(\frac{q_{1}}{q_{0}}\right)}{\log \left(\frac{p_{1} q_{0}}{p_{0} q_{1}}\right)}
$$

Examinando-se (116) observa-se que o valor $a_{m}$ que permite não rejeitar a hipótese $M=M_{0}$ e dessa forma não aconselhar a adoção de controle químico é:

$$
a_{m}=\frac{\log \left(\frac{\beta}{1-\alpha}\right)}{\log \left(\frac{p_{1} q_{0}}{p_{0} q_{1}}\right)}+m k \frac{\log \left(\frac{q_{1}}{q_{0}}\right)}{\log \left(\frac{p_{1} q_{0}}{p_{0} q_{1}}\right)}
$$

Deve-se calcular o valor de $a_{m}$ e de $r_{m}$ para cada valor de $m$ antes de iniciar a amostragem.

Para cada amostra obtida é calculado o número acumulado de insetos $\sum_{i=1}^{m} y_{i}$, correspondente a todas as unidades amostrais examinadas, para cada amostra colhida comparase esse valor com seus respectivos $a_{m}$ e $r_{m}$. Se $\sum_{i=1}^{m} y_{i} \leq a_{m}$ não rejeita-se a hipótese $M=M_{0}$ com probabilidade $\beta$ de erro, desaconselhando o uso de inseticida, caso $\sum_{i=1}^{m} y_{i} \geq r_{m}$ rejeitase $M=M_{0}$ ao nível $\alpha$ de significância e, conseqüentemente, preconiza-se o uso de produtos químicos. Se $a_{m}<\sum_{i=1}^{m} y_{i}<r_{m}$ continua-se a amostragem.

\subsubsection{Representação Gráfica}

As linhas de decisão seguem os modelos matemáticos:

$$
r_{0}=h_{0}+S_{m}
$$




$$
r_{1}=h_{1}+S_{m}
$$

onde $h_{0}$ e $h_{1}$ são coeficientes lineares e $S$ a inclinação das retas.

De (117) e (118) verifica-se que:

$$
\begin{gathered}
h_{0}=\frac{\log \left(\frac{\beta}{1-\alpha}\right)}{\log \left(\frac{p_{1} q_{0}}{p_{0} q_{1}}\right)}, \\
h_{1}=\frac{\log \left(\frac{1-\beta}{\alpha}\right)}{\log \left(\frac{p_{1} q_{0}}{p_{0} q_{1}}\right)}
\end{gathered}
$$

e

$$
S=k \frac{\log \left(\frac{q_{1}}{q_{0}}\right)}{\log \left(\frac{p_{1} q_{0}}{p_{0} q_{1}}\right)}
$$

Ao executar a amostragem os pontos $\left(m_{i} \sum_{i=1}^{m} y_{i}\right)$ são representados no gráfico. Caso o par ordenado estiver em $r_{0}$ ou abaixo, não rejeita-se $M=M_{0}$ com probabilidade $\beta$ de erro, desaconselhando o uso de inseticida.

Caso o par ordenado esteja em $r_{1}$ ou acima, rejeita-se $M=M_{0}$ ao nível $\alpha$ de significância, preconizando o uso de inseticida, enquanto $\left(m ; \sum_{i=1}^{m} y_{i}\right)$ estiver entre as duas retas novas unidades deverão ser examinadas.

\subsubsection{Obtenção da Curva Característica do Teste}

Oakland $^{3}$ mencionado por Estefanel (1977) apresentou a seguinte função distribuição de probabilidade:

$$
f(y ; p)=q^{-k} \frac{(k+y-1) !}{y !(k-1) !}\left(\frac{p}{q}\right)^{y}
$$

${ }^{3}$ OAKL.AND, G.B. An Application of Scqucntial Analysis to Whitcfish Sampling. Biometrics, v.6, p.136139,1950 . 
Dessa forma a equação (16) torna-se:

$$
\sum_{y=0}^{\infty}\left[\left(\frac{q_{1}}{q_{0}}\right)^{-k}\left(\frac{p_{1} q_{0}}{p_{0} q_{1}}\right)^{y}\right]^{h(p)} q^{-k} \frac{(k+y-1) !}{y !(k-1) !}\left(\frac{p}{q}\right)^{y}=1
$$

Multiplicando por $p_{0}$ ambos os termos da razão $q_{1} / q_{0}$ obtém-se:

$$
\left[\frac{1}{\left(p_{0} q_{0}\right)^{h(p)}}\right]^{-k} \sum_{y=0}^{\infty}\left[q\left(p_{0} q_{1}\right)^{h(p)}\right]^{-k} \frac{(k+y-1) !}{y !(k-1) !}\left[\frac{p\left(p_{1} q_{0}\right)^{h(p)}}{q\left(p_{0} q_{1}\right)^{h(p)}}\right]^{y}=1
$$

Comparando com (125) verifica-se que o somatório corresponde a $f\left[y ; p\left(p_{0} q_{1}\right)^{h(p)}\right]$, então:

$$
\left[\frac{1}{\left(p_{0} q_{0}\right)^{h(p)}}\right]^{-k}\left[q\left(p_{0} q_{1}\right)^{h(p)}-p\left(p_{1} q_{0}\right)^{h(p)}\right]^{-k}=1
$$

Desenvolvendo a expressão chega-se:

$$
P=\frac{1-\left(\frac{q_{0}}{q_{1}}\right)^{h}}{\left(\frac{p_{\mathrm{E}} q_{0}}{p_{0} q_{1}}\right)-1}
$$

Considerando $A=\frac{1-\beta}{\alpha}$ e $B=\frac{\beta}{1-\alpha}$ a expressão (30) fica:

$$
L(P)=\frac{\left(\frac{1-\beta}{\alpha}\right)^{h(p)}-1}{\left(\frac{1-\beta}{\alpha}\right)^{h(p)}-\left(\frac{\beta}{1-\alpha}\right)^{h(p)}}
$$

Atribuindo valores pertencentes ao intervalo $[-\infty,+\infty]$ a $h$ em (126) e (127) obtém-se os valores de $P$ e $L(P)$, respectivamente.

\subsubsection{Número Médio de Amostras Necessários ao Teste}

Considerando que a função de probabilidade da distribuição binomial negativa 3:

$$
f(y)=\frac{(k+y-1) !}{y !(k-1) !} \cdot \frac{p^{y}}{q^{k+y}}
$$

então: 


$$
z=\log \frac{f\left(y ; p_{1}\right)}{f\left(y ; p_{0}\right)}=\log \frac{p_{1}^{y}}{q_{1}^{k+y}} \cdot \frac{q_{0}^{k+y}}{p_{0}^{y}}
$$

ou:

$$
z=\log \left[\left(\frac{p_{1}}{p_{0}}\right)^{y}\left(\frac{q_{0}}{q_{1}}\right)^{k}\left(\frac{q_{0}}{q_{1}}\right)^{y}\right]=y \log \frac{p_{1} q_{0}}{p_{0} q_{1}}-k \log \frac{q_{1}}{q_{0}}
$$

O valor esperado de $z$ quando $P$ s o verdadeiro valor do parâmetro da distribuição é:

$$
E_{p}(z)=P \log \frac{p_{1} q_{0}}{p_{0} q_{1}}-k \log \frac{q_{1}}{q_{0}}
$$

Substituindo este valor na expressão (39):

$$
E_{p}(z)=\frac{L(P) \log B+[1-L(P)] \log A}{P \log \frac{p_{1} q_{0}}{p_{0} q_{1}}-k \log \frac{q_{1}}{q_{0}}}
$$

Dividindo o numerador e o denominador por $\log \frac{p_{\mathrm{I}} q_{9}}{p_{0} q_{1}}$ e comparando com (121), (122) e (123) obtém-se:

$$
E_{p}(m)=\frac{L(P)\left(h_{0}-h_{1}\right)+h_{1}}{P-S}
$$

Considerando $M=p k$, tem-se:

$$
E_{p}(m)=\frac{L(M)\left(h_{0}-h_{1}\right)+h_{1}}{M-S}
$$

Atribuindo valores quaisquer a $h$ nas expressões (126) e (127) obtém-se os valores de $P$ e $L(P)$, respectivamente. Fazendo-se $M=p k$ calculam-se os valores de $M$ correspondentes a $P$, com os valores de $M$ e $L(M)$ através da fórmula (126) obtém-se $E_{M}(m)$, esses pontos $\left[M ; E_{M}(m)\right]$ plotados num gráfico permitem traçar a curva do tamanho médio das amostras. 


\section{MATERIAL E MÉTODOS}

\subsection{Material}

\subsubsection{Localização e Período de Amostragem}

O plano de amostragem obtido no presente estudo foi realizado para atender os cultivos de goiaba para mesa da região de Campinas no estado de São Paulo, que é composta de pequenas propriedades com tamanho médio de cinco hectares e onde basicamente é praticada a agricultura familiar, com um bom grau tecnológico.

Os dados utilizados neste trabalho foram obtidos de um estudo de levantamento de insetos-pragas e seus inimigos naturais (predadores e parasitóides) na cultura da goiaba realizado por pesquisadores do Instituto Biológico/APTA da Secretaria de Agricultura e Abastecimento para obtenção de informaçōes a servirem de subsídio na elaboração do MIP para a cultura. O presente estudo foi conduzido em um talhão contendo 39 goiabeiras da variedade "Kumagai" (polpa branca) na propriedade Chácara Ouro Verde localizada a -22,9947 de latitude e $-47,1033^{\circ}$ de longitude, Bairro Pedra Branca no município de Campinas.

Desse levantamento, foram utilizados os dados obtidos durante o período de agosto de 2003 a agosto de 2004 , compreendendo as quatro estações do ano. Em apenas quatro datas de amostragem no ano de 2003 (25 de agosto, 17 de novembro, 1 e 9 de dezembro) e três datas de 2004 (27 de janeiro, 23 de fevereiro e 19 de julho) não foi possível realizar o trabalho de coleta das informações devido a ocorrência de chuvas nesses dias.

Para a coleta dos dados durante as inspegões de levantamento foram utilizados uma planilha padrão previamente elaborada, prancheta e caneta. 


\subsection{Métodos}

\subsubsection{Monitoramento}

As áreas de cultivo se caracterizam por estarem divididas em talhões ou parcelas contendo cerca de 30 a 40 plantas cada um, sendo que cada talhão apresenta todas as plantas em um mesmo estádio fenológico devido à operação de poda total que permite assim uma uniformização, situação esta adequada para aplicação do MIP (Souza Filho \& Costa, 2003).

O número médio de plantas do programa de produção integrada da goiaba e que estão envolvidas no estudo é de 348, distribuídas numa área média de 1,2ha por propriedade.

Para a amostragem do percevejo, o monitoramento foi realizado semanalmente, em 20 (vinte) plantas do talhão, observando-se a presença de insetos (adultos ou ninfas) em ramos localizados no terço médio e superior da copa, em cada quadrante da planta. A cada localização dos insetos em determinado ponto da copa durante a inspeção, era feita a contagem do número de indivíduos ali situados e logo após anotado na planilha padrão.

\subsubsection{Construção do Plano de Amostragem Seqüencial}

Na construção do plano de amostragem foram adotados valores de $\alpha$ (Probabilidade de Ocorrer um Erro Tipo $I$, ou rejeitar $p_{0}$ quando $p_{0}$ ś verdadeiro) e $\beta$ (Probabilidade de Ocorrer um Erro Tipo $I I$, ou aceitar $p_{0}$ quando $p_{0} \leq$ falso)iguais a 0,20 , conforme Southwood (1978) que esses níveis de erro resultam no tamanho de amostra necessária para a tomada de decisão mais viável, na prática, em um sistema de manejo integrado de pragas.

Apesar de vários estatísticos terem desenvolvido uma série de trabalhos pontuais, principalmente nessas últimas décadas, utilizando métodos de análise seqüencial, o artigo original de Wald (1947) com o embasamento metodológico, bem como o trabalho realizado por Estefanel (1977) e por Dantas (2002) foram a base para o desenvolvimento dessa dissertação. Embora não sejam essenciais ao plano de amostragem seqüencial, foram calculados também, a curva característica da operação e a curva do número médio de amostras, para dar idéia do desempenho do plano.

Apesar dos dados originais serem provenientes de contagem, não existe estabelecido até o presente momento, para essa cultura, qual é o nível de dano econômico, ou seja, qual é a menor densidade populacional da praga capaz de causar perdas significativas, sendo assim os dados foram analisados na forma de presência-ausência.

Para se testar o ajuste dos dados a distribuição binomial foi utilizado o teste 
de aderência de $\chi^{2}$ dado pela seguinte expressão:

$$
\chi^{2}=\sum_{i=1}^{N_{c}}\left[\frac{\left(F O_{i}-F E_{i}\right)^{2}}{F E_{i}}\right],
$$

em que $N_{c}$ é o número de classes da distribuição de freqüências, $F O_{i}$, a freqüência observada na i-ésima classe e $F E_{i}$, a freqüência esperada da i-ésima classe. O valor de $\chi^{2}$ calculado é comparado ao valor de $\chi^{2}$ tabelado, com $\left(N_{c}-n p\right)$ graus de liberdade, onde $n p$ é o número de parâmetros estimados em estudo. Se o $\chi^{2}$ calculado é superior ao $\chi^{2}$ tabelado, rejeita-se a hipótese de nulidade, ou seja, de que os dados se ajustam a distribuição teórica em teste.

Foram adotados os valores 0,20 para $p_{1}$ (nível de dano econômico) e 0,10 para $p_{0}$ (nivel de segurança).

As linhas de decisão superior e inferior do teste são definidas, respectivamente, como:

$$
r_{0}=h_{0}+S m
$$

e

$$
r_{1}=h_{1}+S m
$$

$\mathrm{O}$ valor de $m$ indica o número de unidades amostrais a serem utilizadas na amostragem e os valores de $h_{0}, h_{1}$ e $S$ foram obtidos por meio das expressões (49), (50) e (51).

Também foi construída a Curva Característica da Operação $L(p)$, que fornece a probabilidade de acerto na tomada de decisão para um determinado nível de infestação, obtida através da expressão (53).

Por sua vez, a curva do Tamanho Médio de Amostras para não rejeição de $H_{0}$ foi calculado através da expressão (55).

Os softwares utilizados para a construção do plano de amostragem seqüencial foram o SAS, para a parte analítica, e, o Excel, para a parte gráfica. 


\section{RESULTADOS E DISCUSSÃO}

\subsection{Ajuste dos Dados de Presença e Ausência a Distribuição Bi- nomial}

Assim como em Estefanel (1977), ao aplicar o teste de $\chi^{2}$ para verificar o ajuste dos dados a distribuição binomial não foram satisfeitas todas as exigências do plano, uma vez que ocorreram freqüências esperadas inferiores a 1, posto que não foi encontrado nenhum percevejo no período e nas plantas amostradas. Classes com freqüência esperada baixa tendem a elevar o valor do teste calculado e, dessa forma, diminuir o nível de significância.

Em mais de $60 \%$ das amostras analisadas o teste não foi significativo, ou seja, pode-se concluir que as freqüências observadas estão de acordo com as freqüências esperadas e que, portanto os dados se ajustam à distribuição binomial, segundo Barbosa (1982), estudando modelos probabilísticos para a distribuição de $S$. frugiperda, a distribuição binomial é a mais indicada para descrever a proporção de plantas atacadas por essa lagarta.

Tabela 1. Teste qui-quadrado de aderência das frequiências observadas às freqüências esperadas pela distribuição binomial dos dados de presença e ausência para a cultura da goiaba na região de Campinas

\begin{tabular}{cccccc}
\hline Data & Média & Variância & No $^{o}$ g.l. & $\chi_{c}^{2}$ & $\chi_{t}^{2}$ \\
\hline $11 / 08 / 03$ & 10,00 & 5,00 & 1 & 4,555 & 3,841 \\
$18 / 08 / 03$ & 6,00 & 4,20 & 1 & 0,139 & 3,841 \\
$01 / 09 / 03$ & 11,00 & 4,95 & 1 & 6,629 & 3,841
\end{tabular}


Tabela 2. Teste qui-quadrado de aderência das freqüências observadas às freqüências esperadas pela distribuição binomial dos dados de presença e ausência para a cultura da goiaba na região de Campinas

\begin{tabular}{cccccc}
\hline Data & Média & Variância & No g.l. & $\chi_{c}^{2}$ & $\chi_{\boldsymbol{t}}^{2}$ \\
\hline $08 / 09 / 04$ & 9,00 & 4,95 & 1 & 2,869 & 3,841 \\
$15 / 09 / 03$ & 11,00 & 4,95 & 1 & 6,629 & 3,841 \\
$22 / 09 / 03$ & 12,00 & 4,80 & 1 & 9,092 & 3,841 \\
$29 / 09 / 03$ & 7,00 & 4,55 & 1 & 0,661 & 3,841 \\
$06 / 10 / 03$ & 0,00 & 0,00 & 1 & 5,154 & 3,841 \\
$13 / 10 / 03$ & 1,00 & 0,95 & 1 & 3,348 & 3,841 \\
$20 / 10 / 03$ & 0,00 & 0,00 & 1 & 5,154 & 3,841 \\
$27 / 10 / 03$ & 0,00 & 0,00 & 1 & 5,154 & 3,841 \\
$03 / 11 / 03$ & 0,00 & 0,00 & 1 & 5,154 & 3,841 \\
$10 / 11 / 03$ & 0,00 & 0,00 & 1 & 5,154 & 3,841 \\
$24 / 11 / 03$ & 0,00 & 0,00 & 1 & 5,154 & 3,841 \\
$15 / 12 / 03$ & 0,00 & 0,00 & 1 & 5,154 & 3,841 \\
$22 / 12 / 03$ & 0,00 & 0,00 & 1 & 5,154 & 3,841 \\
$29 / 12 / 03$ & 0,00 & 0,00 & 1 & 5,154 & 3,841 \\
$05 / 01 / 04$ & 1,00 & 0,95 & 1 & 3,348 & 3,841 \\
$12 / 01 / 04$ & 1,00 & 0,95 & 1 & 3,348 & 3,841 \\
$19 / 01 / 04$ & 2,00 & 1,80 & 1 & 1,930 & 3,841 \\
$02 / 02 / 04$ & 5,00 & 3,75 & 1 & 0,005 & 3,841 \\
$10 / 02 / 04$ & 4,00 & 3,20 & 1 & 0,259 & 3,841 \\
$16 / 02 / 04$ & 4,00 & 3,20 & 1 & 0,259 & 3,841 \\
$01 / 03 / 04$ & 13,00 & 4,55 & 1 & 11,942 & 3,841 \\
$08 / 03 / 04$ & 8,00 & 4,80 & 1 & 1,571 & 3,841 \\
$15 / 03 / 04$ & 4,00 & 3,20 & 1 & 0,259 & 3,841 \\
$22 / 03 / 04$ & 7,00 & 4,55 & 1 & 0,661 & 3,841 \\
$29 / 03 / 04$ & 5,00 & 3,75 & 1 & 0,005 & 3,841 \\
$05 / 04 / 04$ & 8,00 & 4,80 & 1 & 1,571 & 3,841 \\
$12 / 04 / 04$ & 10,00 & 5,00 & 1 & 4,555 & 3,841
\end{tabular}


Tabela 3. Teste qui-quadrado de aderência das frequiências observadas às frequiências esperadas pela distribuição binomial dos dados de presença e ausência para a cultura da goiaba na região de Campinas

\begin{tabular}{cccccc}
\hline Data & Média & Variância & № g.l. & $\chi_{c}^{2}$ & $\chi_{t}^{2}$ \\
\hline $19 / 04 / 04$ & 9,00 & 4,95 & 1 & 2,869 & 3,841 \\
$26 / 04 / 04$ & 11,00 & 4,95 & 1 & 6,629 & 3,841 \\
$03 / 05 / 04$ & 14,00 & 4,20 & 1 & 15,180 & 3,841 \\
$10 / 05 / 04$ & 9,00 & 4,95 & 1 & 2,869 & 3,841 \\
$17 / 05 / 04$ & 12,00 & 4,80 & 1 & 9,092 & 3,841 \\
$24 / 05 / 04$ & 2,00 & 1,80 & 1 & 1,930 & 3,841 \\
$31 / 05 / 04$ & 5,00 & 3,75 & 1 & 0,005 & 3,841 \\
$07 / 06 / 04$ & 5,00 & 3,75 & 1 & 0,005 & 3,841 \\
$14 / 06 / 04$ & 6,00 & 4,20 & 1 & 0,139 & 3,841 \\
$21 / 06 / 04$ & 4,00 & 3,20 & 1 & 0,259 & 3,841 \\
$28 / 06 / 04$ & 7,00 & 4,55 & 1 & 0,661 & 3,841 \\
$05 / 07 / 04$ & 3,00 & 2,55 & 1 & 0,900 & 3,841 \\
$12 / 07 / 04$ & 6,00 & 4,20 & 1 & 0,139 & 3,841 \\
$26 / 07 / 04$ & 7,00 & 4,55 & 1 & 0,661 & 3,841 \\
$02 / 08 / 04$ & 2,00 & 1,80 & 1 & 1,930 & 3,841 \\
$09 / 08 / 04$ & 1,00 & 0,95 & 1 & 3,348 & 3,841 \\
$16 / 08 / 04$ & 0,00 & 0,00 & 1 & 5,154 & 3,841 \\
\hline & & & & &
\end{tabular}




\subsection{Plano de Amostragem Seqüencial com Níveis de Erro Iguais a} 0,20

As expressões utilizadas para descrever as linhas de decisões que podem ser visualizadas na Figura 1 , são $S_{0}=-1,70951+0,14524^{*} m$ reta até a qual não rejeita-se $H_{0}$ e $S_{1}=+1,70951+0,14524^{*} m$ a partir da qual não rejeita-se $H_{1}$.

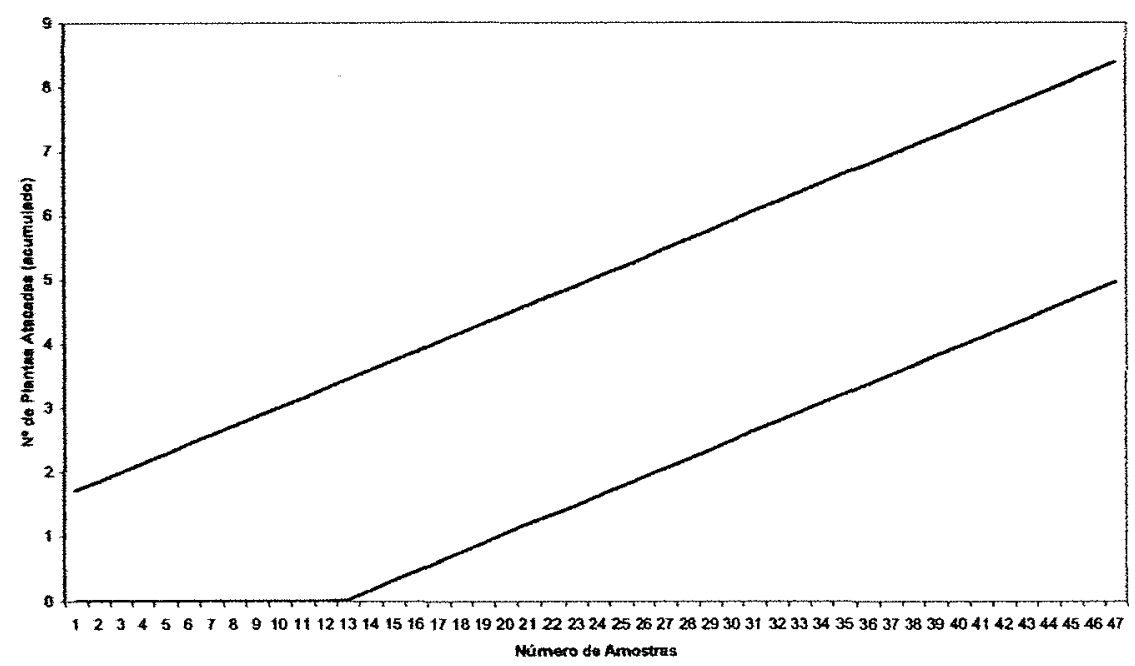

Figura 1 - Plano de Amostragem Seqüencial para o Número de Plantas Atacadas com por pelo Menos Um Percevejo Leptoglossus stigma com base na Distribuição Binomial

A partir da Figura 1 foi construído uma tabela de amostragem, visando facilitar o trabalho do "pragueiro"ou técnico responsável pelo monitoramento (Tabela 4). A tomada de decisão só pode ser realizada a partir da $13^{a}$ unidade amostral, sendo que o número máximo esperado de unidades amostrais é de 24 elementos. 
Tabela 4. Plano de amostragem seqüencial para avaliar a infestação de percevejos na cultura da goiaba

\begin{tabular}{|c|c|c|c|}
\hline Plantas amostradas & $\begin{array}{l}\text { Limite } \\
\text { Inferior }\end{array}$ & $\begin{array}{c}N^{o} \text { de plantas } \\
\text { infestadas }\end{array}$ & $\begin{array}{c}\text { Limite } \\
\text { Superior }\end{array}$ \\
\hline 1 & & & \\
\hline 2 & & & \\
\hline 3 & & & \\
\hline 4 & & & \\
\hline 5 & & & \\
\hline 6 & & & \\
\hline 7 & & & \\
\hline 8 & & & \\
\hline 9 & & & \\
\hline 10 & & & \\
\hline 11 & & & \\
\hline 12 & 0 & & 3 \\
\hline 13 & 0 & & 4 \\
\hline 14 & 0 & & 4 \\
\hline 15 & 0 & & 4 \\
\hline 16 & 1 & & 4 \\
\hline 17 & 1 & & 4 \\
\hline 18 & 1 & & 4 \\
\hline 19 & 1 & & 4 \\
\hline 20 & 1 & & 5 \\
\hline 21 & 1 & & 5 \\
\hline 22 & 1 & & 5 \\
\hline 23 & 2 & & 5 \\
\hline 24 & 2 & & 5 \\
\hline
\end{tabular}


A Tabela 4 deve ser interpretada da seguinte forma: a cada planta inspecionada deve se anotar " 1 "(caso seja encontrado pelo menos um percevejo) e "0" caso contrário na coluna "No de Plantas Infectadas", esse valor é acumulativo, ou seja, a cada nova amostragem ele pode permanecer igual ao anterior (no caso de não ser encontrado nenhum percevejo na nova planta) ou ser acrescentado uma unidade (caso contrário).

Quando o número acumulado de arvores infestadas for inferior a coluna da esquerda ("Limite Inferior") suspende-se a amostragem e não existe necessidade de aplicação de agrotóxicos, caso o valor acumulado seja major que a coluna da direita ("Limite Superior"), rejeita-se a hipótese de que a praga está abaixo do nível de dano econômico e, portanto, há necessidade de efetuar o controle da praga.

O processo deve continuar até que se tome uma dessas duas decisões ou que se atinja o número máximo de 24 plantas vistoriadas; se isso ocorrer e não for possível tomar nenhuma decisão, o "pragueiro" ou o técnico responsável pelo monitoramento deve retornar num período de tempo que seja igual a metade do que é utilizado normalmente para inspeção da cultura.

\subsection{Curva Característica da Operação e Curva do Tamanho Médio de Amostras}

A curva característica da operação $(L(p))$ está representada na Figura 2, tem por objetivo fornecer a probabilidade de se tomar uma decisão correta para um determinado nível de infestação, dessa forma observa-se que quando o valor de $\mathrm{p}$ for de 0,05 , isto é, $5 \%$ de plantas com pelo menos um percevejo, o teste tem $97 \%$ de probabilidade de aceitar $H_{0}$, e quando este mesmo índice de infestação for de $26 \%$ a probabilidade de não recomendar alguma ação de controle é de $6 \%$. 


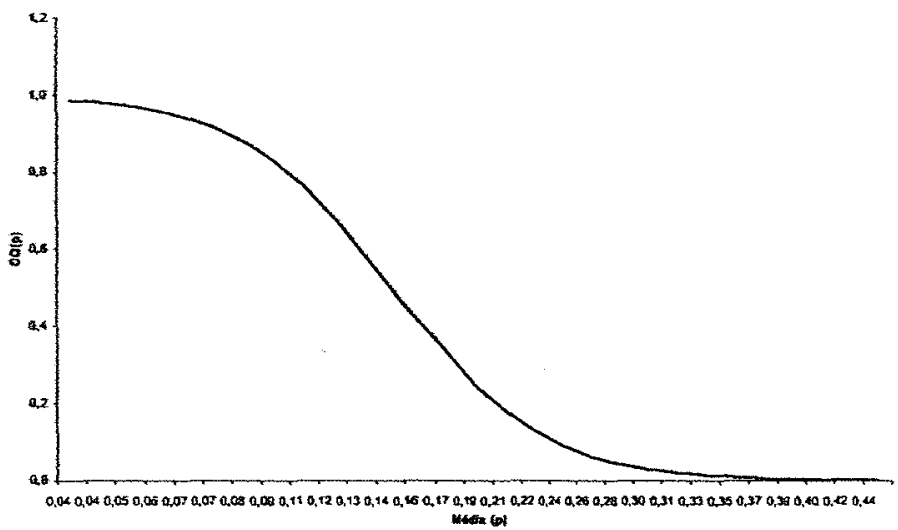

Figura 2 - Curva Característica de Operação do teste de Razão de Verossimilhança para a população total de Percevejos

Na curva do tamanho médio de amostras representados pela Figura 3, está de acordo com Wald (1945), o qual afirma que o valor máximo de unidades amostrais recomendadas para que ocorra alguma decisão acontece quando $p_{0}<p<p_{1}$. Para o presente estudo o valor de p que conduziu ao maior valor de amostra foi de $13 \%$ ou 0,13 .

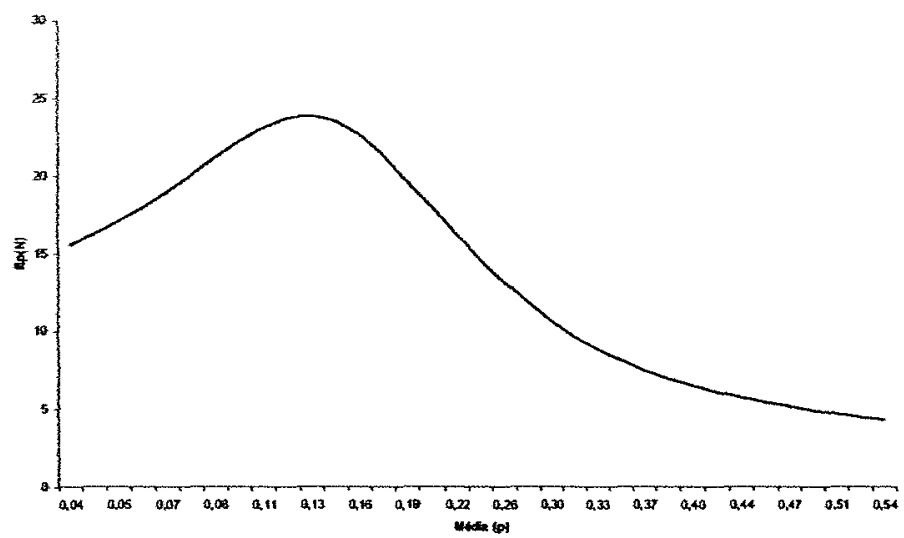

Figura 3 - Curva do Tamanho Esperado de Amostras do teste Seqüêncial da Razão de Verossimilhança para a População Total de Percevejos

Para propriedades com infestação igual a $14 \%$ espera-se que o número médio de amostras necessários para se chegar a uma conclusão sobre aplicar ou não inseticidas seja de 24 unidades e, para uma média de infestação igual a 0,35 seriam necessários 8 elementos. 


\section{CONCLUSÕES}

Com base na metodologia utilizada e nos dados estudados nesse trabalho, podese concluir que:

i) Os dados de presença e ausência do percevejoo Leptoglossus stigma ajustaram-se a distribuição binomial;

ii) O número máximo de amostras esperado, para se tomar a decisão, encontra-se em torno de 24, considerando os níveis de erro iguais a 0,20 ;

iii) O plano foi desenvolvido inicialmente para controlar uma das principais pragas da cultura da goiaba de mesa da região de Campinas no interior do Estado de São Paulo, ou seja, em municípios que apresentam características de regime climático e relevo semelhantes.

A proposta original deste trabalho foi cumprida, desenvolvendo um plano de amostragem seqüencial para o percevejo Leptoglossus stigma (Hemiptera: Coreidae), utilizando para isso o teste da razão de probabilidades de Wald (1945). 


\section{REFERÊNCIAS BIBLIOGRÁFICAS}

AGRIANUAL. Anuário da Agricultura Brasileira. São Paulo. 2005. 520p.

ANSCOMBE, F. J. The statistical analysis of insect counts based on the negative binomial distribution. Biometrics, v. 5, p. 165-173, 1949.

BARBOSA, J. C. Distribuições de probabilidades como base para análises estatísticas, amostragem e estratégias de manejo de Diatraea saccharalis (Fabr. 1794) na cultura de cana de açúcar. 1985. 135p. Tese (Doutorado) - Escola Superior de Agricultura "Luiz de Queiroz", Universidade de São Paulo.

BARBOSA, J. C.; PERECIN, D. Modelos probabilísticos para a distribuição de lagartas Spodoptera frugiperda na cultura do milho. Científica, v. 10, p.181-191, 1982.

BEARZOTI, E.; AQUINO, L. H. Plano de amostragem seqüencial para avaliação de infestação de bicho mineiro (Lepdoptera: Lyonetiidae) no sul de Minas Gerais. Pesquisa Agropecuária Brasileira, v. 29, n. 5, p. 697-705, 1994.

COCHRAN, W. G. Sampling techniques. 3. ed. New York: Jonh Wiley, 1977. 428p.

DANTAS, I. M. Distribuição espacial e plano de amostragem seqüencial para a lagarta minador dos citros - Phyllocnistis citrella (Stainton 1856) (Lepdopetera: Gracillariidae) em laranjeira 'pera-rio' Citrus sinensis (L.) Osbeck. Jaboticabal, 2002. 63p. Tese (Doutorado) - Faculdade de Ciências Agrárias e Veterinarias, Universidade Estadual Júlio de Mesquita Filho.

DAVIS, P. M. Statistics for describing populations. In: PEDIGO, L. P.; BUNTIN, G. D.. Handbook of sampling methods for arthopods in agriculture. Boca Ranton: CRC Press, 1993. p. 33-54. 
ELLIOTT, J. M. Some methods for the statistical analysis of sample of benthic invertebrates. Ambrleside: Freshwater Biological Association, 1979. 148p.

ESTEFANEL, V. A amostragem seqüencial baseada no teste seqüencial da razão de probabilidades e seu uso no controle das lagartas da soja no estado do Rio Grande do Sul. Piracicaba, 1977. 117p. Dissertação (Mestrado) - Escola Superior de Agricultura "Luiz de Queiroz", Universidade de São Paulo.

FARIAS, P. R. S.; BARBOSA J. C.; BUSOLI, A. C. Amostragem seqüencial (PresençaAusência) para Spodoptera frugiperda (J. E. Smith) (Lepidoptera: Noctuidae) na cultura do milho. Neotropical Entomology. v. 30, n. 4, p. 691-695, 2001.

FERNANDES, O.A. Ecologia dos insetos. In: GUEDES, J.C.; COSTA, I.D.; CASTIGLIONI, E. (Coords.) Bases e técnicas do manejo de insetos. Santa Maria: UFSM/CCR/DFS, Pallotti, 2000. p. 51-57.

FUNDAÇÃO INSTITUTO BRASILEIRO DE GEOGRÁFIA E ESTATÍSTICA. Produção Agrícola Municipal. Brasil: IBGE, 2002. Disponível em http: www.ibge.gov.br, em 01 de março de 2005.

GHOSH, B. K.; SEN, P. K. Handbook of sequential analysis. New York: Marcel Dekker, 1991. 637p.

GRAVENA, S.; FERNANDES, O. A.; PAZINI, W. C. Amostragem seqüencial para os ácaros da falsa ferrugem Phyllocoptruta oleivora (Ashm.) e da leprose Brevipalphus phoenicis (Geisks) no manejo integrado de pragas dos citros. Laranja, n.9, p.147-160, 1988.

HUFFAKER, C. B. New technology of pest control. New York: Wiley Interscience, 1980. p.

JACOMINO, A. P.; PIZA JÚNIOR, C. L.; MURACAMI, J. Y. et al. Manejo integrado de pragas na cultura da goiaba. Brotas, 2002.

KOGAN, M. Criação de insetos, bases nutricionais e aplicações em programas de manejo de pragas. Fundação Cargill, Campinas: 1980. p. 45-75.

LI, S. Y.; FITZPATRICK, S. M. Monitoring obliquebanded leafroller (Lepidoptera: Tortricidae) larvae and adults on raspberries. Enviromental Entomology, v.26, n. 2, p.170-177, 1997. 
LUNA, J. M., FLEISCHER, S. J., ALLEN, W. A. Development and validation of sequencial sampling plans for potato leafhopper (Homoptera: Cicadellidae) in alfalfa. Enviromental Entomology, v. 12, n. 6, p. 1690-1694, 1983.

MEDINA, J. C., Goiaba: cultura, matéria prima, processamento e aspectos econômicos. Campinas: , 1988. p.1-120

MOLLET, J. A.; TRUMBLE, J. T.; SEVACHERIAN, V. Comparison of dispersion and regression indices Tetranychus cinnabarinus (Boisduval) (Acari: Tetranychidae) populations in cotton. Enviromental Entomology, v. 13, n. 6, p. 1511-1514, 1984.

NORRIS, R.F.; CASWELL-CHEN, E.P.; KOGAN, M. Concepts in integrated pest management. Prentice Hall: New Jersey, 2003. 586p.

PEÑA, J. E.; BARANOWSKI, R. M. Dispersion indices and sampling plans for the broad mite (Acari: Tarsonemidae) and the citrus rust mite (Acari: Eriophyidae) on limes. Environmental Entomology, v. 19, n. 2, p. 378-382, 1990.

PERECIN, D.; BARBOSA, J. C. Amostragem e análise estatística de dados de distribuição de contágio. Revista de Matemática e Estatística, v. 10, p. 207-216, 1992.

ROZANE, D.E.; OLIVEIRA, D.A.; LIRIO, V.S. Importância econômica da cultura da goiabeira. In: ROZANE, D.E; COUTO, F.A.A.; EMPRESA JUNIOR DE AGRONOMIA (Eds.) Cultura da Goiabeira: Tecnologia e Mercado. Viçosa: UFV, EJA, 2003. p.1-19.

SHEPARD, M.; CARNER, G. R. Distribution of insects in soybean field. The Canadian Entomologist, v. 108, p. 767-771, 1976.

SHIELDS, E. J.; SPECKER, D. R. Sampling for potato leafhopper (Homoptera: Cicadellidae) on alfalfa in New York: relative efficiency of three sampling methods and development of a sequential sampling plan. Journal of Economic Entomology, v. 82, n. 4, p. 1091-1095, 1989.

SILVEIRA NETO, S. Manejo de Pragas, Botucatu: Editora Universidade Estadual Paulista, 1990a. p. 71-86. 
SILVEIRA NETO, S. Monitoramento e decisão no controle de pragas. In: CROCOMO, W.B. (Org.). Manejo Integrado de Pragas. Botucatu: UNESP; São Paulo: CETESB, 1990b. p.71-86.

SOUTHWOOD, T. R. E. Ecological methods. 2. ed. New York: John Wiley, 1978. 525p.

SOUZA FILHO, M.F.; COSTA, V.A.. Manejo integrado de pragas da goiabeira. In: ROZANE, D.E; COUTO, F.A.A.; EMPRESA JUNIOR DE AGRONOMIA (Eds.) Cultura da Goiabeira: Tecnologia e Mercado. Viçosa: UFV, EJA, 2003. p.177-206.

SOUZA, J.C.; RAGA A.; SOUZA, M.A. Pragas da goiabeira. Boletim Técnico. EPAMIG: Belo Horizonte-MG. 2003. $N^{\circ} 71.60 p$.

TAYLOR, L. R. Assessing and interpreting the spatial distributions of insect populations. Annual Review of Entomology, v. 29, p. 321-357, 1984.

VILLACORTA, A.; TORNERO, M. T. T. Plano de amostragem seqüencial de dano causado por Perileucoptera coffeella no Paraná. Pesquisa Agropecuária Brasileira, v. 17, n. 9, p. 1249-1257, 1982.

WALD, A. Sequential tests of statistical hypothesis. Annals of Mathematical Statistics, v. 16 , p. 117-186, 1945.

WALD, A. Sequential Analysis, New York: John Wiley, 1947. 212p.

YOUNG, J. L.; YOUNG, J. H. Statistical ecology: a population perspective. London: Kluwer Academic, 1998. 565p. 